\title{
Translational Regulation of Pmt1 and Pmt2 by Bfr1 Affects Unfolded Protein O-Mannosylation
}

\author{
Joan Castells-Ballester ${ }^{1}$, Natalie Rinis ${ }^{1}{ }^{\circledR}$, Ilgin Kotan ${ }^{2}$, Lihi Gal ${ }^{3}{ }^{\circledR}$, Daniela Bausewein ${ }^{1,4}$, \\ Ilia Kats ${ }^{2}$, Ewa Zatorska ${ }^{1}$, Günter Kramer ${ }^{2}$, Bernd Bukau ${ }^{2}$, Maya Schuldiner ${ }^{3}$ D and \\ Sabine Strahl 1,* \\ 1 Centre for Organismal Studies (COS), Glycobiology, Heidelberg University, D-69120 Heidelberg, Germany; \\ jocasbal@gmail.com (J.C.-B.); natalia.rinis@cos.uni-heidelberg.de (N.R.); \\ daniela.bausewein@cos.uni-heidelberg.de (D.B.); ewa.zatorska@cos.uni-heidelberg.de (E.Z.) \\ 2 Center for Molecular Biology of Heidelberg University (ZMBH), German Cancer Research Center (DKFZ), \\ ZMBH-DKFZ Alliance, D-69120 Heidelberg, Germany; i.kotan@zmbh.uni-heidelberg.de (I.K.); \\ i.kats@zmbh.uni-heidelberg.de (I.K.); g.kramer@zmbh.uni-heidelberg.de (G.K.); \\ bukau@zmbh.uni-heidelberg.de (B.B.) \\ 3 Department of Molecular Genetics, Weizmann Institute of Science, Rehovot 7610001, Israel; \\ lihi.gal@weizmann.ac.il (L.G.); maya.schuldiner@weizmann.ac.il (M.S.) \\ 4 spm $^{2}$-Safety Projects \& More GmbH, D-69493 Hirschberg a. d. Bergstraße, Germany \\ * Correspondence: sabine.strahl@cos.uni-heidelberg.de; Tel.: +49-6221-54-6286
}

Received: 15 November 2019; Accepted: 6 December 2019; Published: 10 December 2019

\begin{abstract}
O-mannosylation is implicated in protein quality control in Saccharomyces cerevisiae due to the attachment of mannose to serine and threonine residues of un- or misfolded proteins in the endoplasmic reticulum (ER). This process also designated as unfolded protein O-mannosylation (UPOM) that ends futile folding cycles and saves cellular resources is mainly mediated by protein O-mannosyltransferases Pmt1 and Pmt2. Here we describe a genetic screen for factors that influence O-mannosylation in yeast, using slow-folding green fluorescent protein (GFP) as a reporter. Our screening identifies the RNA binding protein brefeldin A resistance factor 1 (Bfr1) that has not been linked to O-mannosylation and ER protein quality control before. We find that Bfr1 affects O-mannosylation through changes in Pmt1 and Pmt2 protein abundance but has no effect on PMT1 and PMT2 transcript levels, mRNA localization to the ER membrane or protein stability. Ribosome profiling reveals that Bfr1 is a crucial factor for Pmt1 and Pmt 2 translation thereby affecting unfolded protein O-mannosylation. Our results uncover a new level of regulation of protein quality control in the secretory pathway.
\end{abstract}

Keywords: Bfr1; endoplasmic reticulum; mannosyltransferase; RNA binding; O-mannosylation; Pmt; protein quality control; translation; UPOM

\section{Introduction}

Glycosylation is a major protein modification that includes the addition of a sugar moiety onto a protein [1]. Two types of glycosylation conserved from fungi to humans are $\mathrm{N}$-glycosylation and O-mannosylation [2]. Both essential types of glycosylation start in the endoplasmic reticulum (ER) and share the common mannose donor Dol-P-mannose (Dol-P-Man). O-mannosylation entails the direct transfer of mannose from Dol-P-Man to serine and threonine residues of proteins entering the secretory pathway (herein referred to as secretory proteins) by different types of protein O-mannosyltransferase enzymes. Among those, only the protein O-mannosyltransferase (PMT) family is conserved among eukaryotes [3-7]. Changes in PMT-based O-mannosylation in humans result in genetic disorders called 
$\alpha$-dystroglycanopathies [8] and are also associated with various cancers $[9,10]$. In the baker's yeast, S. cerevisiae, (from here on termed simply yeast) O-mannosylation in the ER depends on PMTs only, making it an ideal model to study this crucial protein modification.

PMTs are ER membrane glycoproteins that have been shown to associate with the translocon to modify translocating polypeptides [11]. In yeast the redundant PMT family contains seven members, for six of which the O-mannosyltransferase activity has been proven. They are subdivided into three subfamilies referred to as PMT1 (Pmt1, Pmt5), PMT2 (Pmt2, Pmt3, Pmt6), and PMT4 (Pmt4) that show distinct substrate specificities [12]. Pmt1-Pmt2 heterodimers contribute a major part of O-mannosyltransferase activity [13].

Analysis of the yeast O-mannose glycoproteome revealed that around 20\% of all ER and Golgi proteins are O-mannosylated, many of those with crucial functions in protein glycosylation, folding, quality control, and trafficking [14]. Hence it is not surprising that transcription of PMTs is enhanced under ER stress conditions [15] and general PMT inhibition induces the unfolded protein response (UPR) [16], a transcriptional response that regulates protein folding capacities of the ER and degradative processes termed ER associated degradation (ERAD) of un- or misfolded proteins [17].

While most studies of O-mannosylation focus on the role of this modification during normal protein maturation along the secretory pathway, recently it has been demonstrated that there exists non-canonical O-mannosylation of proteins due to un- or misfolding [18]. This so-called unfolded protein O-mannosylation (UPOM) has been proposed as a molecular timer that is active in the early stages of ER protein quality control to abrogate futile folding cycles and save valuable cellular resources [19]. The consequences of UPOM strongly depend on the substrate proteins which have been shown to be later eliminated by the cell either by ERAD [20], vacuolar degradation [21] or cellular exclusion [22]. To date this modification has been observed for several mutated proteins, however, not for their wild type counterparts [20-25]. Central regulators of UPOM have been shown to be Pmt1 and Pmt2 but not Pmt4 $[19,26]$. The most prominent UPOM substrate to date is slow-folding green fluorescent protein (GFP) that folds properly in the cytosol, but when targeted to the ER is recognized as a misfolded protein due to its slow folding and therefore gets O-mannosylated [19]. O-mannosylation itself then blocks further folding of the fluorophore, resulting in decreased fluorescence intensity and rendering this protein an adequate reporter to monitor UPOM efficiency.

With the exception of Pmt1 and Pmt2 that mediate UPOM this protein quality control system is poorly defined. In the present study we screened for cellular factors that affect UPOM in yeast. To this end we took advantage of ER-targeted slow-folding GFP as a UPOM-reporter and identified brefeldin A resistance factor 1 (Bfr1) as an enhancer of Pmt1 and Pmt2 translation.

\section{Results}

\subsection{Genome-Wide Screen Reveals Bfr1 as a Factor Influencing UPOM}

To perform a genome-wide screen for identification of cellular factors affecting UPOM we took advantage of the model UPOM substrate, slow-folding ER-GFP [19]. We stably introduced ER-GFP into the innocuous $H O$ locus of $p m t 1 \Delta, p m t 2 \Delta$, and pmt $4 \Delta$ cells. ER targeting of GFP was ensured by an N-terminal Kar2 signal peptide and ER retention by a C-terminal HDEL retention signal (Figure 1A, upper scheme). A fast folding variant of GFP $\left(\mathrm{ER}-G F P_{\mathrm{f}}\right)$ that escapes O-mannosylation and therefore changes in folding and fluorescence served as a negative control [27]. As shown in Figure 1B, ER-GFP shows reduced fluorescence compared to ER-GFP $\mathrm{f}$ expressed in wild type cells. In pmt1 $\Delta$ and pmt2 $\Delta$ cells reporter fluorescence is considerably enhanced compared to wild type whereas the GFP signal in pmt4 $\Delta$ is not affected (Figure 1B,C). These results are in line with previously published data in which ER-GFP is expressed from a centromeric plasmid [19]. O-mannosylation of ER-GFP in wild type and PMT deletion mutants was monitored by probing lysates of respective cells for GFP (Figure 1D). ER-GFP detection results in a main GFP signal accompanied by multiple higher molecular weight bands that are not seen in case of ER-GFP $($ Figure 1D, compare area designated by the white arrow 
in lanes 2 and 3). The same GFP pattern is detected in PMT4 deficient (lane 6) but not PMT1 and PMT2 deficient cells (lanes 4 and 5) and correlates with O-mannosylation of ER-GFP. Treatment of immunopurified FLAG-tagged ER-GFP (Figure 1A, lower scheme) with $\alpha 1-2,3,6$ mannosidase that removes O-linked $\alpha$-mannose [28] confirmed that the signal above the main GFP band emanates from O-mannosyl glycans (Figure 1E). We further examined whether ER-GFP expression that is driven by the strong TDH3 promotor induces ER stress resulting in UPR induction (Figure 1F). In contrast to ER-GFP $_{\mathrm{f}}$, expression of ER-GFP triggers the UPR as indicated by the significant increase of mRNA levels of the spliced (active) variant (Figure 1F, HAC1s) of the UPR-inducing transcription factor Hac1 and the UPR-targeted Hsp70 chaperone Kar2. This suggests that at least in the case of GFP, slow folding rates rather than protein overexpression constitute the biggest challenge for the ER.

As depicted in Figure 2A, the ER-GFP expressing wild type strain was crossed with libraries containing viable deletion strains of non-essential genes and hypomorphic mutants of essential ones, to create new libraries in which each haploid strain expresses the ER-GFP on the background of one mutant allele. The median fluorescence intensities (MFIs) of all viable strains resulting upon crossing are shown in Figure 2B (small diagram on the right) and a detailed listing of all identified targets is available in Supplementary Table S1. Analysis of ER-GFP median intensity frequency distribution for more than 5000 viable mutant strains revealed that approximately $5 \%$ displayed fluorescence exceeding the MFI range of ER-GFP in wild type cells (Figure 2B, zoomed in area and green bars in bar diagram). A total of 109 genes exceeded the threshold (median GFP intensity at 187, red dotted line in Figure 2B) and were considered as positive hits (supplementary Table S1). Validity of the screen was confirmed by the presence of PMT1 (position 38) and PMT2 (position 3) among the positive candidates. Further analysis of screening hits was performed by manual assessment of GFP signal localization to the ER. Out of 109 candidates, only spf1 $\Delta$ cells showed predominant cytosolic GFP fluorescence further confirmed in an independent spf1 $\Delta$ mutant by fluorescence microscopy (Supplementary Figure S1A). SPF1 encodes an ER membrane P-type ATPase important for maintenance of $\mathrm{Ca}^{2+}$ homeostasis and normal lipid composition of intracellular membranes [29,30]. Among the residual 108 candidates, stress pathway components (e.g., oca $1 \Delta$ and oca $2 \Delta$ involved in oxidative stress response; $\sin 1 \Delta, p t c 1 \Delta$ and sic1 $\Delta$ encoding for functional components of the high osmolarity glycerol (HOG) pathway) and components of N-glycosylation and quality control (e.g., ost3 $\Delta$ (Supplementary Figure S2) and cwh41 $\Delta$ ) were present. Analysis of the O-mannosylation status of the canonical Pmt1-Pmt2 client Hsp150 revealed that the vast majority of the mutants do not severely affect O-mannosylation in general, judging by the prevalence of the molecular mass of Hsp150 upon the gene deletions. However, in a substantial number of mutants, we observed the presence of subspecies of Hsp150 that likely result from general maturation defects (Supplementary Table S1). Among those are for example ost $3 \Delta$ and pop $2 \Delta$ (Supplementary Figure S1B) that affect N-glycosylation and mRNA catabolism, respectively, and for which general defects in protein homeostasis have been reported previously [31,32]. Since we were especially interested in candidates that directly affect glycosylation of the UPOM-reporter, systematic analysis of candidate genes was performed by determining ER-GFP O-mannosylation by Western blot. This revealed that for most of the tested mutant strains increased GFP fluorescence did not correlate with significantly reduced O-mannosylation (Supplementary Table S1). Next to pmt1 $\Delta$ and $p m t 2 \Delta$, only two additional mutants were found to abrogate ER-GFP O-mannosylation: $b f r 1 \Delta$ (Figure $2 \mathrm{C}, \mathrm{D}$ ) and $p s a 1^{\mathrm{DAmP}}$ (Supplementary Figure S3A). PSA1 is an essential gene encoding for the enzyme GDP-mannose pyrophosphorylase that is responsible for the synthesis of GDP-mannose, the mannose donor in Dol-P-Man synthesis [33] (Supplementary Figure S3B). Since decreased expression of Psa1 in the $p s a 1^{D A m P}$ most likely limits availability of the mannose donor Dol-P-Man thereby affecting PMT activity, we decided to herein focus on BFR1 whose role remains unknown. Enhanced ER-GFP fluorescence upon BFR1 deletion was confirmed via flow cytometry in several independent mutants (Supplementary Figure S4). 
A

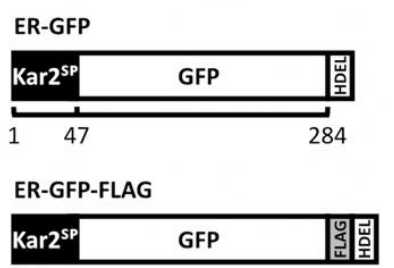

B

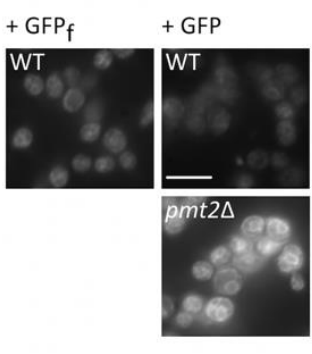

C

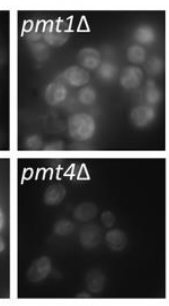

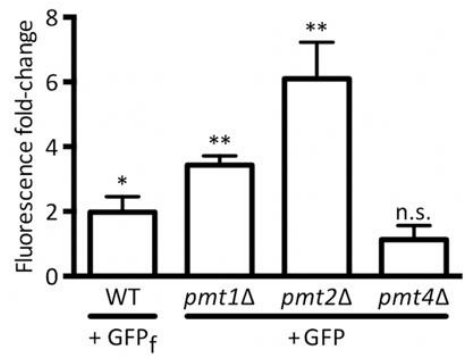

D

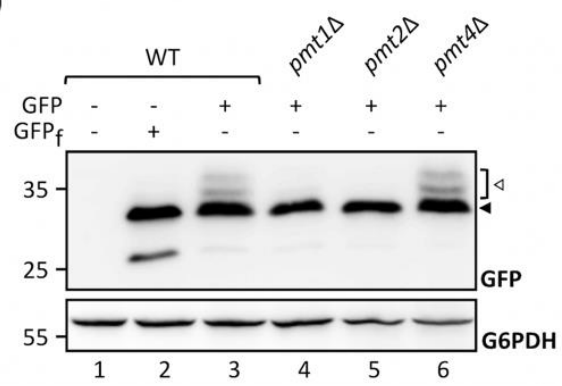

$\mathbf{E}$
$\mathbf{F}$
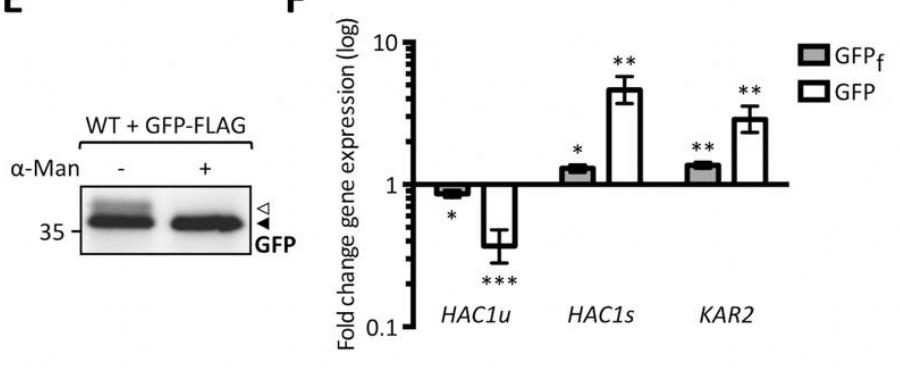

Figure 1. Analysis of ER-GFP as a unfolded protein O-mannosylation (UPOM)-reporter. (A) Schematic representation of ER-GFP N-terminally fused to the endoplasmic reticulum (ER) targeting signal peptide from Kar2 and C-terminally fused to the HDEL ER retention sequence (upper panel) and scheme of FLAG-tagged ER-GFP used for immunoprecipitation in (C) (lower panel). Fluorescence analysis of wild type and $p m t \Delta$ strains with genomically integrated ER-GFP by microscopy (B) and flow cytometry

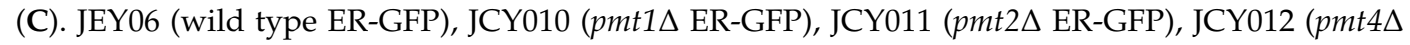
ER-GFP), and JEY05 (wild type expressing ER-GFP ${ }_{\mathrm{f}}$ as negative control) cells were grown in yeast extract-peptone-dextrose (YPD) before being imaged under standard conditions (scale bar $10 \mu \mathrm{m}$ ) (B) or analyzed by flow cytometry (C). In (C) fluorescent signals resulting from analysis of 20,000 cells were normalized to wild type and results are plotted as fold-change. Error bars represent the range of values from three independent experiments. For statistical significance one-sample $t$-test was performed on $\log _{2}$ (fold change). (D) Western blot analysis of ER-GFP O-mannosylation in total cell extracts from strains shown in (B) and (C). $20 \mu \mathrm{g}$ of protein were resolved on a 12\% PAA gel and detection was performed with an anti-GFP antibody. Wild type cells expressing ER-GFP $_{\mathrm{f}}$ served as negative control and G6PDH was used as loading control. Arrows on the right indicate the main GFP signal (black arrow) and signals emanating from higher O-mannosylated GFP fractions (white arrow). (E) FLAG-tag immunoprecipitation of ER-GFP on total cell extracts from wild type cells expressing FLAG-tagged ER-GFP from the pN014 plasmid. Purified ER-GFP-FLAG-HDEL was subjected to $\alpha 1-2,3,6$ mannosidase treatment overnight at $37{ }^{\circ} \mathrm{C}$ and resolved on a $12 \%$ PAA gel. Detection was performed with an anti-GFP antibody. The signals emanating from higher O-mannosylated GFP-fractions (white arrow) collapse upon treatment into the main GFP signal (black arrow). Results are representative of two independent experiments. (F) RT-PCR analysis of HAC1u, HAC1s, and KAR2 mRNA levels in wild

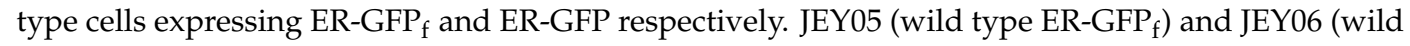
type ER-GFP) cells were grown in YPD, total RNA was extracted, and cDNA was prepared and used as a template for RT-PCR. Fold-change was calculated from three independent experiments with respect to ACT1 mRNA and error bars represent the confidence interval. For statistical significance one-sample $t$-test was performed on $\log _{2}-\Delta \Delta \mathrm{Ct}$. N.s. $=$ not significant. Asterisks report on statistical significance: ${ }^{*} p \leq 0.05,{ }^{* *} p \leq 0.01,{ }^{* * *} p \leq 0.001$. 
A

GFP genomic integration $\quad \triangle / D A m P$ libraries

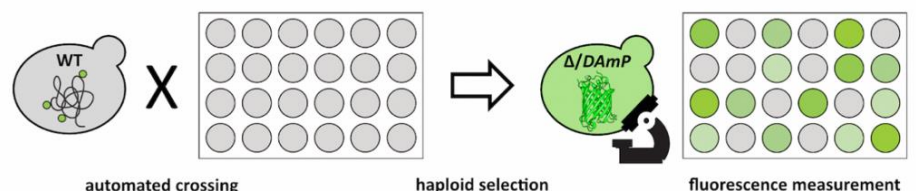

B
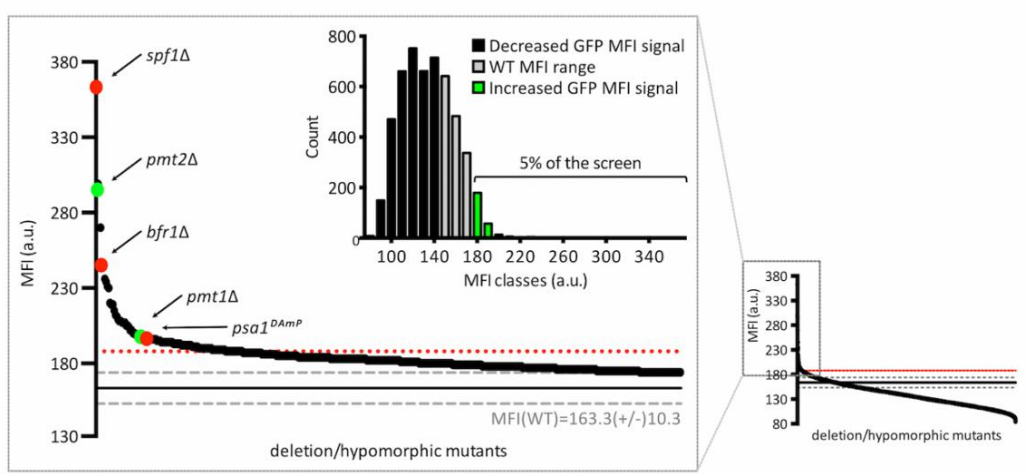

C
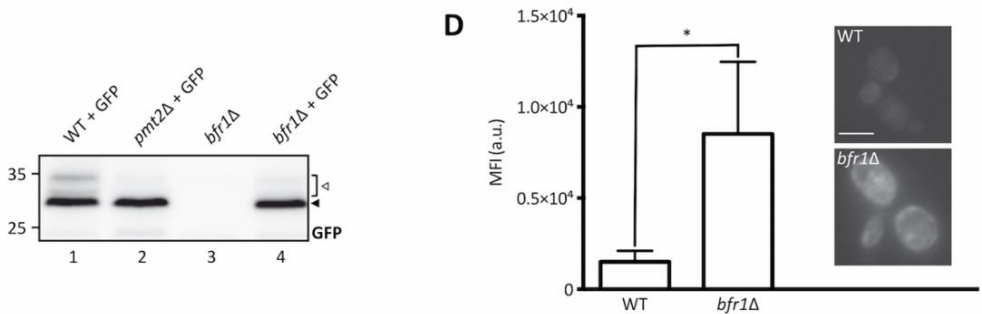

Figure 2. Identification of brefeldin A resistance factor 1 (Bfr1) in a genome-wide UPOM screen. (A) Schematic flowchart representing the major steps of the genome-wide high-throughput screen for identification of UPOM factors using ER-GFP as a fluorescent reporter. In brief, the ER-GFP expressing JEY06 strain was crossed with the yeast deletion library [34] and the DAmP library [35] on 1536 colony format YPD plates. Obtained diploids were selected for ER-GFP as well as deletion/DAmP mutations using KanR and URA3 respectively. Sporulation was induced upon nitrogen starvation for 7 days and haploid cells were selected on SD plates with aforementioned selections as well as toxic amino acid derivatives to eliminate residual diploids. Haploids were immobilized on Concanavalin A coated 384 well format microscopy plates and analyzed using an automated microscopy setup [36]. (B) Graphic representation of screening results. The small graph on the right represents the median fluorescence intensity (MFI) distribution of mutant strains (x-axis) analyzed within the UPOM screen. The magnified region on the left contains mutants that display fluorescence intensities that exceed the range of wild type MFI (163.6 +/- 10.3, indicated by grey dashed lines). The threshold for positive hit selection is marked by a red dotted line. Colored dots depict expected hits (PMT1 and PMT2 in green) and hits that were further analyzed (SPF1, BFR1, and PSA1 in red). The bar graph on the upper left represents the median intensity frequency distribution of all mutant strains. Bars in grey depict frequencies of mutant strains with fluorescence within the wild type MFI range. Black and green bars represent frequencies of mutant strains with GFP signals below or above the wild type MFI range respectively. (C) Western blot analysis of ER-GFP O-mannosylation in total cell extracts from wild type (BY4741) and bfr1 $\Delta$ strains from the ER-GFP screen. Equivalents to $0.2 \mathrm{OD}_{600}$ were resolved on a $12 \%$ PAA gel and detection was performed with an anti-GFP antibody. A pmt $2 \Delta$ strain expressing ER-GFP served as a positive control. Arrows on the right indicate the main GFP signal (black arrow) and signals emanating from higher O-mannosylated GFP fractions (white arrow). In bfr1 $\Delta$ cells no higher O-mannosylated GFP fractions are detected. (D) JEY06 (wild type) and a de novo generated $b f r 1 \Delta$ strain in which ER-GFP was genomically integrated were grown in YPD media before being analyzed by flow cytometry or imaged under standard conditions (scale bar $5 \mu \mathrm{m}$ ). Fluorescent signal resulting from analysis of 20,000 cells via flow cytometry was normalized to wild type and error bars represent the range of values from three independent experiments. For statistical significance one-sample $t$-test was performed on $\log _{2}$ (fold change). Asterisks report on statistical significance: ${ }^{*} p \leq 0.05$. 


\subsection{Bfr1 Affects UPOM by Modulating Pmt1 and Pmt2 Protein Levels}

BFR1 was identified in a genetic screen as a multicopy suppressor of brefeldin A induced lethality in yeast [37]. It is associated with mRNA metabolism as it was shown to interact with the RNA binding protein Scp160 in polyribosome associated mRNP complexes [38]. Since then mRNA related functions of Bfr1 have gained increasing attention: Bfr1 was shown to affect P-body formation $[39,40]$ and to bind hundreds of mRNAs despite the fact that it lacks canonical RNA binding domains [41,42].

Considering the role of Bfr1 in mRNA metabolism and the recent finding that Bfr1 binds PMT1 and PMT2 transcripts [42], we hypothesized that Bfr1 could affect UPOM by modulating Pmt1 and Pmt2 protein levels. We therefore analyzed Pmt1 and Pmt2 protein abundance in wild type versus bfr $1 \Delta$ cells (Figure $3 \mathrm{~A}, \mathrm{~B}$, left panels). Our results show that Pmt 1 and Pmt 2 protein levels are markedly reduced in BFR1 deficient versus wild type cells. This holds true under ER stress conditions caused by the ER-GFP reporter in the screening strain background (compare lanes 2 and 4 in Figure 3A,B) with Pmt1 and Pmt2 levels increased in response to UPR (compare lanes 1 and 2 in Figure 3A,B), as well as in the absence of ER-GFP in an independent strain background (compare lanes 1 and 3 in Figure 3A,B). Quantification of PMT protein levels reveals a significant 2-fold reduction for both PMTs (Figure 3A,B, right panels) in bfr1 $\Delta$ versus wild type cells.

Since Bfr1 binds to numerous mRNAs, we investigated the effect of BFR1 deletion on protein levels of representative Bfr1 interactors [42] involved in protein import such as the main translocon subunit Sec61 [43], quality control such as the Hsp70 chaperone Kar2 [44] and N-glycosylation such as oligosaccharyl transferase (OST) subunits Ost3 and $\mathrm{Wbp} 1[45,46]$. We also analyzed protein levels of the GPI-anchored protein Gas1 that is highly O-mannosylated [47] (Figure 3C). Results show no major changes in protein levels for any of these Bfr1 targets in wild type versus bfr $1 \Delta$ cells (compare lane 1 with 3 and 2 with 4 in Figure 3C), suggesting that Bfr1 binding to mRNA alone is not sufficient to affect protein abundance.

To further substantiate the finding that O-mannosylation defects observed upon BFR1 deletion result directly from decreased protein levels of Pmt1 and Pmt2, we performed a functional rescue experiment by overexpressing Pmt2. As shown in Figure 4A, Pmt2 overexpression restores O-mannosylation of ER-GFP in BFR1 deficient cells. In agreement Pmt2 overexpression significantly reduces GFP fluorescence detected in $b f r 1 \Delta$ cells, however, not to wild type levels (Figure 4B). In BFR1 deficient cells Pmt2 protein levels are markedly decreased compared to wild type (Figure 4C, compare lanes 1 and 3), even upon Pmt2 overexpression (compare lanes 2 and 4) and irrespective of ER stress caused by ER-GFP expression (compare lane 5 with 7 and 6 with 8). Inability to restore native Pmt2 levels as well as reduced levels of Pmt1, may explain why full complementation of ER-GFP O-mannosylation could not be gained. Taken together, our data show that the aberrant O-mannosylation of ER-GFP in $b f r 1 \Delta$ cells is a direct consequence of decreased Pmt 1 and Pmt2 protein levels and that Bfr1 affects UPOM by controlling the abundance of these enzymes. 
A

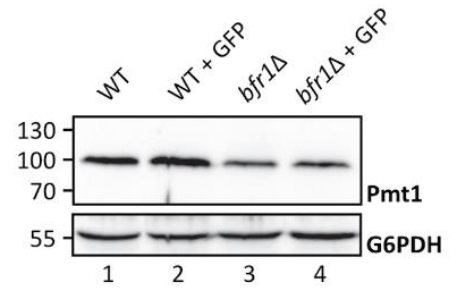

B

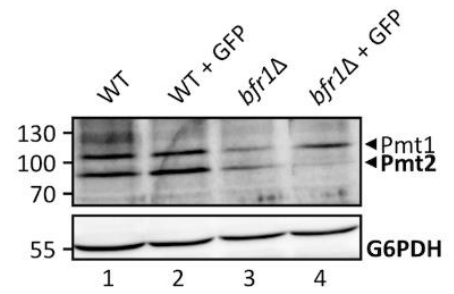

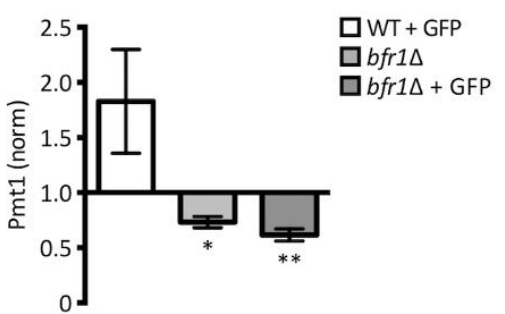

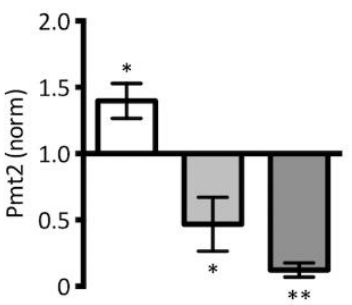

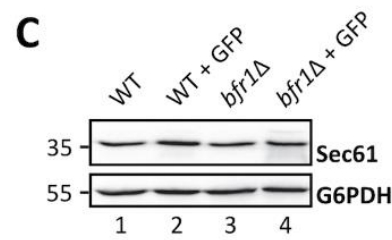
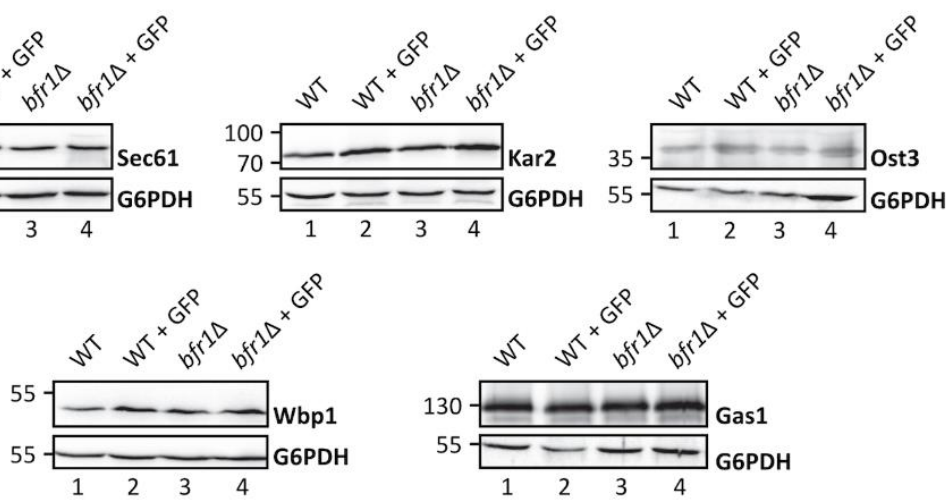

Figure 3. Pmt1 and Pmt2 protein levels are reduced in BFR1 deficient cells. Western blot analysis of protein levels of Pmt1 (A), Pmt2 (B), and other representative proteins known to be targeted by Bfr1 [42] (C) in total cell extracts from wild type (BY4741), JEY06 (wild type ER-GFP), bfr1 $\Delta$ and bfr1 $1 \Delta$ ER-GFP strains. (A) and (B) left panels: $20 \mu \mathrm{g}$ of protein were resolved on a 12\% PAA gel and detection was performed with an anti-Pmt1 and anti-Pmt2 antibody respectively. Pmt2 detection was initially performed with a polyclonal serum detecting Pmt1 at the same time (lower and upper band indicated by black arrows respectively). In subsequent experiments preabsorption of the polyclonal serum was performed on membranes from PMT2 deficient cells (single band detection for Pmt2 in e.g., Figure 4). G6PDH was used as loading control. (A) and (B) right panels: Western blot signals were quantified using Image Studio Lite v 5.2 and PMT signals were first normalized to the respective G6PDH signals and subsequently normalized to the Pmt/G6PDH ratio calculated for wild type cells. Error bars represent the range of values from three independent experiments. For statistical significance one-sample $t$-test was performed on $\log _{2}$ (fold change). (C) $20 \mu \mathrm{g}$ of protein were resolved on a $12 \%$ PAA gel and detection was performed with the indicated antibodies. G6PDH was used as loading control and results are representative of three independent experiments. Asterisks report on statistical significance: ${ }^{*} p \leq 0.05,{ }^{* *} p \leq 0.01$. 

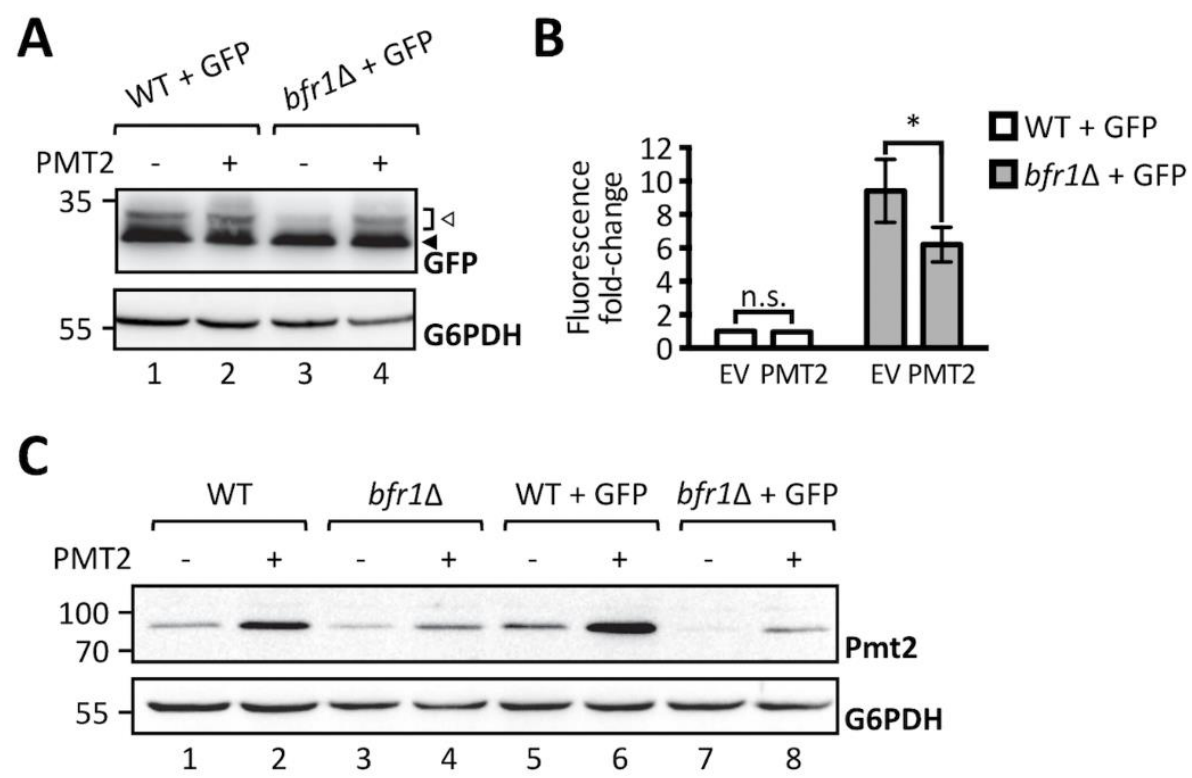

Figure 4. Pmt2 overexpression partially rescues loss of ER-GFP O-mannosylation in bfr1 $\Delta$ cells. (A) Western blot analysis of ER-GFP O-mannosylation in total cell extracts from JEY06 (wild type ER-GFP) and $b f r 1 \Delta$ ER-GFP strains transformed with either pRS41N (empty vector) or pJC09 (PMT2). Strains were grown under standard conditions in YPD supplemented with nourseothricin for selection. Twenty micrograms of protein were resolved on a 12\% PAA gel and detection was performed with an anti-GFP antibody. G6PDH was used as loading control. Arrows on the right indicate the main GFP signal (black arrow) and signals emanating from higher O-mannosylated GFP fractions (white arrow). Pmt2 overexpression partially restores ER-GFP O-mannosylation in the $b f r 1 \Delta$ strain. (B) Flow cytometry analysis of strains described in (A). Fluorescent signal for each strain resulted from analysis of 20,000 cells and statistical significance was assessed by a 2 way ANOVA on three independent experiments. Pmt2 overexpression partially restores ER-GFP fluorescence to the level detected in the JEY06 strain. (C) Western blot analysis of Pmt2 protein levels in total cell extracts from wild type (BY4741), bfr1 $\Delta$, JEY06 (wild type ER-GFP), and bfr1 1 ER-GFP strains transformed with either pRS41N (empty vector) or pJC09 (PMT2) and grown as in (A). Twenty micrograms of protein were resolved on a 12\% PAA gel and detection was performed with an anti-Pmt2 antibody. G6PDH was used as loading control. N.s. $=$ not significant. Asterisks report on statistical significance: ${ }^{*} p \leq 0.05$.

\subsection{Bfr1 Affects Pmt1 and Pmt2 Protein Levels on a Posttranscriptional Level}

We next analyzed whether Bfr1 affects PMT transcript levels by measuring PMT1 and PMT2 mRNA abundance in wild type versus bfr1 $\Delta$ cells (Figure 5A). No significant changes in mRNA levels for both PMTs were found. To exclude impact of mRNA 5' regions, PMT2 was placed under the control of a GAL1 inducible promotor and Pmt2 protein as well as transcript levels were assessed in wild type versus mutant cells. Pmt 2 protein levels were markedly reduced in BFR1 deficient cells (Figure 5B, compare lanes 3 and 4) whereas transcript levels were unaffected (Figure 5C). These results pointed to a posttranscriptional control of PMT synthesis mediated by either reduced translation or reduced protein stability in bfr $1 \Delta$ cells. Cycloheximide chase experiments demonstrated that protein stability was not affected in bfr $1 \Delta$ mutants (Figure 5D), suggesting a possible effect of Bfr1 on translation efficiency. 
A

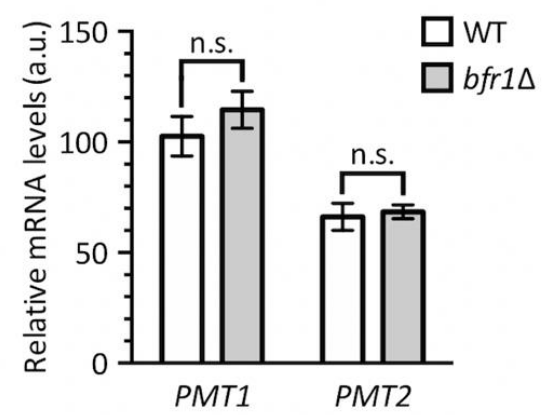

C

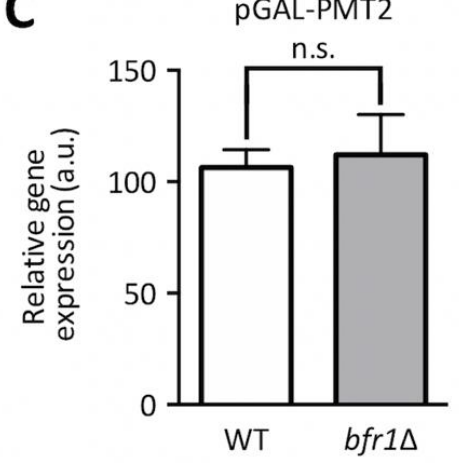

B

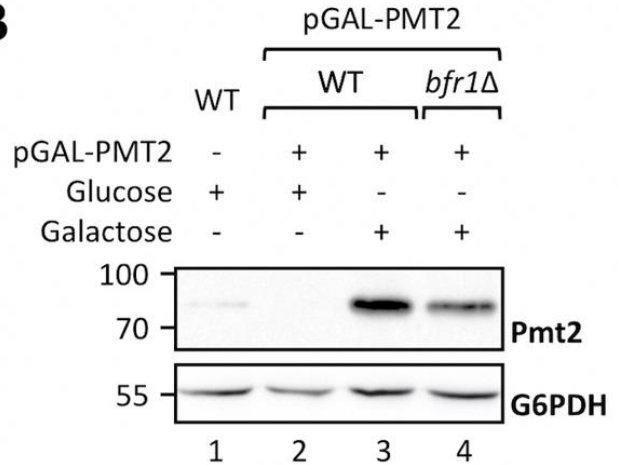

D

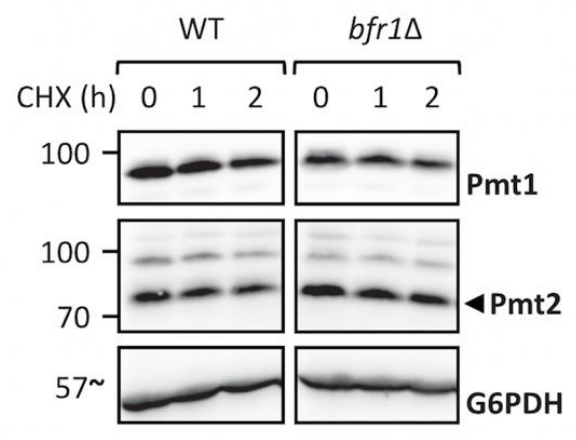

Figure 5. BFR1 deletion does not affect PMT1 and PMT2 transcription. (A) RT-PCR analysis of PMT1 and PMT2 mRNA levels in wild type (BY4741) and bfr1 $\Delta$ strains. Cells were grown in YPD medium, total RNA was extracted and cDNA was prepared and used as a template for RT-PCR. Results show mRNA abundance with respect to TAF10 mRNA from three independent experiments \pm SD. For statistical significance a multiple $t$-test was performed. (B) Western blot analysis of Pmt2 protein levels expressed under the control of a GAL1 inducible promotor in total cell extracts from strains described in (A) upon addition of indicated sugars. (C) RT-PCR analysis of PMT2 mRNA levels in strains described in (A) in which Pmt2 is expressed under the control of a GAL1 inducible promotor upon growth in galactose containing media. Results show mRNA abundance with respect to ACT1 mRNA from three independent experiments \pm SD. For statistical significance an unpaired $t$-test was performed. (D) Cycloheximide chase analysis of Pmt1 and Pmt2 in wild type (BY4741) and bfr1 $\Delta$ strains. Cycloheximide was added to a final concentration of 100 to $200 \mu \mathrm{M}$ and equal amounts of cells were sampled at indicated time points and subjected to Western blot analysis using Pmt1 and Pmt2 antibodies. G6PDH served as a loading control. N.s. = not significant.

\subsection{BFR1 Deletion Does Not Affect PMT1 and PMT2 mRNA Localization to the ER}

Cotranslational protein translocation requires targeting of mRNAs encoding for secretory proteins to the ER membrane [48] and implies recognition of the signal sequence by the signal recognition particle for delivery to the translocon $[49,50]$. Additional concepts, however, have emerged that postulate translation independent mRNA recruitment by ER membrane associated RNA binding proteins [51]. In this case transcript recruitment is mediated by cis elements present on the mRNA itself and trans-acting RNA binding proteins [52]. Given that Bfr1 mainly interacts with polysomes associated with the ER membrane [38] and that Bfr1 interacting mRNAs are enriched for secretory proteins [42] we analyzed whether PMT1 and PMT2 transcript localization was affected in $b f r 1 \Delta$ cells by subcellular fractionation. To this end soluble and membrane fractions of total cell extracts from $b f r 1 \Delta$ cells were separated by ultracentrifugation and PMT2 transcript levels were analyzed in both fractions (Figure 6A,B). The calculated PMT2 mRNA ratio of membrane to soluble fraction is approximately 1 for wild type cells indicating equal distribution of PMT2 between both fractions. In BFR1 deficient cells the PMT2 mRNA ratio does not significantly change (Figure 6B). 
A

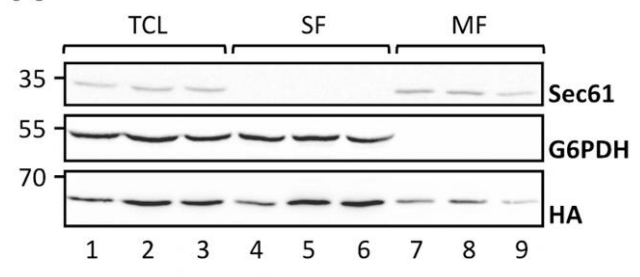

B

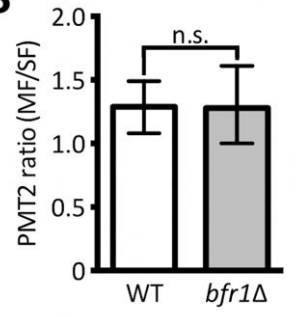

C
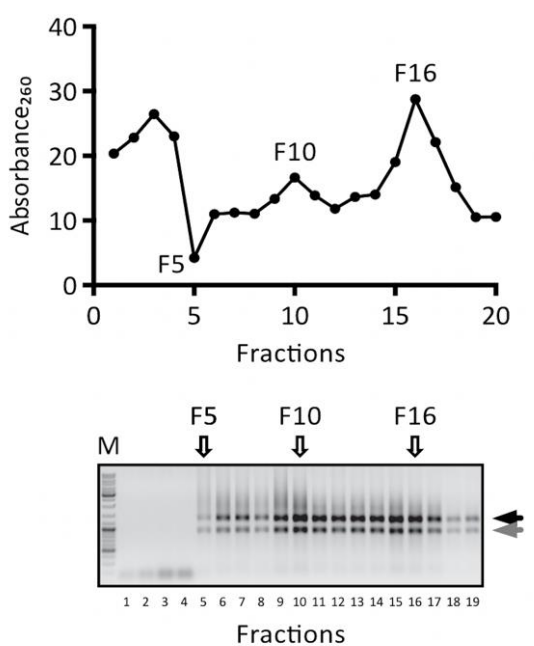

$\begin{array}{llllll}\text { D } & \text { TCL } & \text { F5 } & \text { F10 } & \text { F16 }\end{array}$

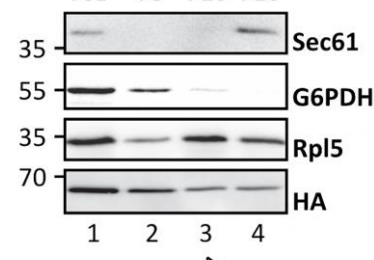

$E$

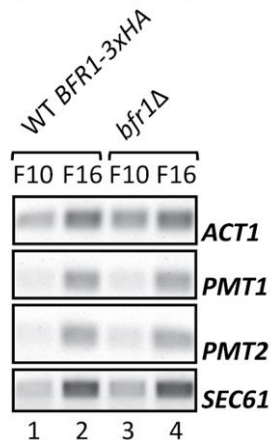

Figure 6. BFR1 deletion does not affect PMT1 and PMT2 transcript localization. (A) and (B): JCY017 (wild type BFR1-3xHA) cells were grown in YPD medium, lysed and total cell extracts were subjected to one step ultracentrifugation. (A) Western blot analysis of total cell lysates (TCL), soluble and membrane fractions (SF and MF respectively) upon one step ultracentrifugation. Equivalents to 0.25 $\mathrm{OD}_{600}$ were resolved on a $12 \%$ PAA gel and detection was performed with the indicated antibodies. Sec61 served as a membrane marker and G6PDH as a cytosolic marker. Bfr1-3xHA was detected using the HA-tag. (B) RT-PCR analysis of PMT2 mRNA from soluble and membrane fractions upon one step ultracentrifugation. Total RNA was extracted from respective fractions and cDNA was prepared. PMT2 mRNA from each fraction was normalized to ACT1 mRNA. Results show the average membrane to soluble PMT2 mRNA ratio from three independent experiments and error bars represent the confidence interval. For statistical significance one-sample $t$-test was performed on $\log 2^{-\Delta \Delta C t}$. (C), (D), and (E): JCY017 (wild type BFR1-3xHA) and bfr1 $\Delta$ cells were grown in YPD medium, lysed and total cell extracts were subjected to sucrose step gradient centrifugation. (C) Absorbance 260 profile of fractions collected upon sucrose step gradient centrifugation (upper panel) and agarose gel electrophoresis of equivalent amounts of each fraction (lower panel). F5, F10, and F16 indicate fractions selected for further analysis. Black and grey arrows next to the agarose gel depict ribosomal subunits 605 and 40S. (D) Western blot analysis of total cell lysates (TCL) and selected sucrose gradient fractions from JCY017 (wild type BFR1-3xHA) cells. $0.25 \mathrm{OD}_{600}$ units of total cell extract and equivalents of selected fractions were resolved on a $12 \%$ PAA gel and detection was performed with the indicated antibodies. Sec61 and G6PDH were detected exclusively in fractions F16 and F5 respectively confirming successful fractionation. The ribosomal protein Rpl5 was mainly detected in fractions F10 and F16 that represent cytoplasmic and membrane bound polysomes respectively. The weaker Rpl5 signal detected in fraction F5 probably emanates from free cytosolic ribosomes. (E) Semi-quantitative PCR analysis of PMT1 and PMT2 mRNA from sucrose gradient fractions F10 and F16 from JCY017 (wild type BFR1-3xHA) and bfr1 $\Delta$ cells. Total RNA was extracted from respective fractions, cDNA was prepared and a 1:20 dilution was used as template in a standard DreamTaq PCR reaction. ACT1 that served as a loading control also shows strong engagement in the ER membrane containing fraction F16 in line with reports that the ER is a general translation hub even for cytosolic proteins [53]. Results are representative of two independent fractionations. N.s. = not significant. 
In addition, total cell extracts from wild type cells expressing fully functional HA-tagged Bfr1 and bfr $1 \Delta$ cells were fractionated on a sucrose step gradient. Analysis of the RNA content of 20 collected fractions showed enrichment of ribosomes in fractions F10 and F16 (Figure 6C). The respective control experiment was performed with EDTA supplemented lysates and resulted in the shift of both Absorbance $_{260}$ peaks observed for F10 and F16 to soluble fractions in line with ribosomal disassembly (Supplementary Figure S5). Analysis of specific marker proteins within F5, F10, and F16 reveals efficient separation of cytosolic and membrane fractions (Figure 6D, compare lanes 2 and 4). All analyzed fractions contain ribosomes as assessed by the ribosomal protein Rpl5, however, to different extents. F10 represents the cytoplasmic polyribosome fraction whereas F16 contains ER membrane bound polysomes (Figure 6D, compare Sec61 in lanes 3 and 4). Bfr 1 was found throughout fractions consistent with reports of this cytosolic protein being associated with polyribosomes. Analysis of mRNA content in ribosome containing fractions F10 and F16 in wild type cells showed strong engagement of PMT1, PMT2, and SEC61 mRNA with ER membrane associated ribosomes, whereas only minor amounts of these mRNAs were detectable in the cytoplasmic fraction F10 (Figure 6E, lanes 1 and 2 respectively). In BFR1 deficient cells distribution of neither PMT1 and PMT2 mRNAs nor SEC61 and ACT1 mRNAs was changed compared to wild type cells. In combination our data show that PMT2 transcripts are equally distributed between the cytosolic and ER membrane bound polysomal fraction and that PMT1 and PMT2 mRNAs preferentially colocalize with membrane bound polyribosomes irrespective of Bfr1 presence.

\subsection{Bfr1 Affects Pmt1 and Pmt2 Translation}

Next, we analyzed translation dynamics in wild type versus $b f r 1 \Delta$ cells by ribosome profiling, which provides a quantitative and high-resolution profile of in vivo translation and is based on deep sequencing of ribosome protected mRNA fragments [54]. Protein synthesis rates are derived from average ribosomal density along mRNAs based on two fundamental assumptions: That all ribosomes complete translation and that elongation rates are similar among different mRNAs [55]. Ribosomal densities along transcripts show active translation and provide a snapshot of protein synthesis within the cell, independent of transcript levels.

Ribosome profiling was performed in duplicate for both wild type and BFR1 deficient cells. Replicates showed high correlation of reads per million mapped reads (RPM) values $\left(r^{2}=0.99\right.$ and $\mathrm{r}^{2}=0.97$ for wild type and $b f r 1 \Delta$ cells, respectively) (Supplementary Figure S6A; Supplementary Table S2). RPM values of wild type and bfr1 $\Delta$ cells also showed high correlation $\left(r^{2}=0.97\right)$ (Supplementary Figure S6B; Supplementary Table S2) ruling out a generalized effect on translation. Statistical analysis revealed comparable subsets of genes significantly up- or downregulated at 0.01 false discovery rate (FDR) (red dots on Figure 7A). For Pmt1 and Pmt2 ribosome profiling data demonstrate a bfr $1 \Delta$ to wild type ratio of averaged RPMs of 0.581 and 0.596 respectively that corresponds to a significant 1.7-fold decrease of ribosomal footprint density and therefore active protein synthesis in BFR1 deficient cells. This decrease in active translation correlates with the approximate 2-fold decrease in PMT protein abundance detected in bfr $1 \Delta$ cells (Figure 3A,B). In line with this observation, active translation of representative Bfr1 targets whose expression levels did not change upon BFR1 deletion (Figure 3C), remain unaffected with the exception of Kar2 (wild type/bfr1 $\Delta=0.582$ ) (Supplementary Table S2). Since PMT1 and PMT2 transcript levels do not change between wild type and mutant cells whereas ribosomal density is 1.7-fold lower, these results reveal Bfr1 as a translational enhancer of Pmt1 and Pmt2. Furthermore, we combined our ribosomal footprint data with the Bfr1 mRNA interactome unraveled by Lapointe et al. [42]. The 174 strongest mRNA interactors (Figure 7B, class A) include 104 mRNAs encoding for proteins of the secretome (filled dots) defined by Ast et al. [56]. Translation of 35 mRNAs, all encoding secretome proteins, is significantly reduced in absence of $B F R 1$, suggesting that Bfr1 preferentially affects translation of ER-targeted proteins. Intriguingly, GO functional annotation clustering identified among those targets, protein glycosylation (PMT1, OST1, 
PMT2, PMT3, PMT4, KTR1, STT3, ALG12) and ergosterol biosynthesis (ERG24, ERG3, NCP1, ERG4, $E R G 11)$ as major functional clusters, pointing to Bfr1 as an important factor governing these processes.
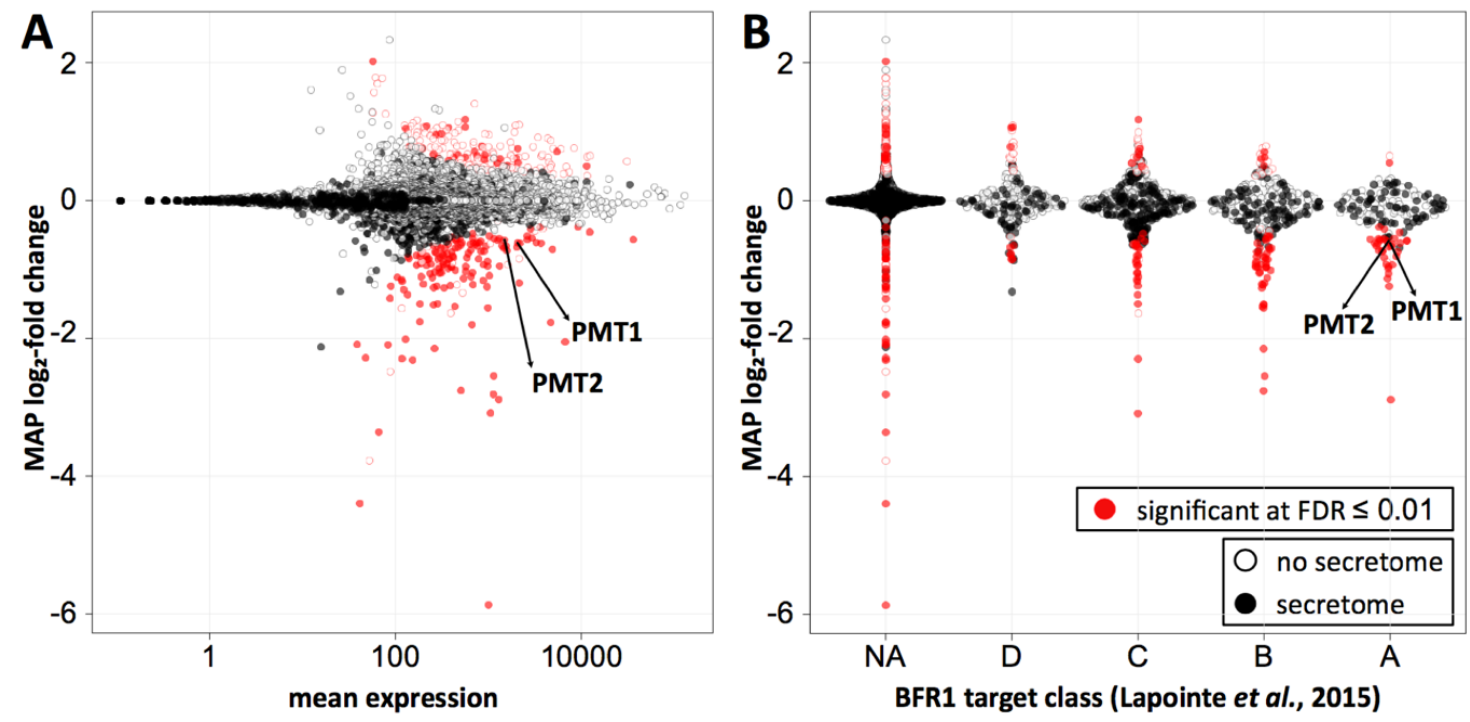

Figure 7. Bfr1 significantly enhances active translation of Pmt1 and Pmt2 and of a subgroup of secretory pathway proteins whose transcripts are strong Bfr1 interactors. (A) MA plot showing active translation in bfr1 $\Delta$ compared to wild type. Proteins for which translation is significantly affected in bfr1 $\Delta$ versus wild type cells are depicted in red with filled red dots representing proteins assigned to the secretory pathway according to [56]. Pmt1 and Pmt2 translation is significantly reduced in bfr1 $\Delta$ cells. (B) Ribosome profiling data were combined with data from an in vivo RNA tagging approach performed for Bfr1 [42]. Classes A-D outlined in [42] contain candidates that are bound by Bfr1 to different extents: The strongest binders are in class A. In classes A and B most significantly affected proteins are down- rather than upregulated and are assigned to the secretory pathway [56]. Pmt1 and Pmt2 are found among significantly downregulated proteins in class A. In (A) and (B) $\log 2$-fold changes were shrunken towards 0 using a Cauchy prior [57], the mode of the posterior distribution is shown. The amount of shrinkage is proportional to the gene-specific variance. FDR $=$ false discovery rate, $\mathrm{NA}=$ not assigned.

\section{Discussion}

In recent years, protein O-mannosylation proved to be critically important for ER protein quality control. O-mannosylation affects ER protein homeostasis at different levels. On one hand, stress sensors as well as other crucial components of protein folding and quality control machineries carry O-mannosyl glycans which may directly impact on their function [14,58]. On the other hand, un- or misfolded proteins receive O-mannosyl glycans which label them for ER clearance [59]. In a first effort to identify factors that affect UPOM, the Pmt1-Pmt2 complex proved to be a central hub for ER protein quality control.

Among our screening hits we find several mutants that probably impact on ER protein folding but do not directly affect O-mannosylation of the UPOM-reporter (Supplementary Table S1). An example is INO2 that encodes for a transcription factor responsible for derepression of phospholipid biosynthetic genes [60]. Membrane phospholipid perturbations have been linked to chronic ER stress in S. cerevisiae [61]. The presence of INO2 as well as SPF1 that was reported to cause ergosterol deficiency in the ER [62] further emphasizes the importance of ER membrane integrity to maintain the ER as a robust folding compartment in general. Most of the candidates, however, are linked to protein quality control as components of stress related pathways such as $\sin 1 \Delta, p t c 1 \Delta$ and $\operatorname{sic} 1 \Delta$ that encode functional components of the high osmolarity glycerol pathway (HOG pathway), as well as oca $1 \Delta$ and $o c a 2 \Delta$ that are involved in oxidative stress. Basal activity of the HOG pathway 
was shown to contribute to UPR induced accumulation of glycerol and thereby mediates resistance towards the ER stress inducing agent tunicamycin in S. cerevisiae [63]. Osmolytes such as glycerol are often referred to as "chemical chaperones" and have been shown to increase protein stability and restore ER homeostasis [64]. Increased fluorescence of ER-GFP in oca1 $\Delta$ and oca $2 \Delta$ mutants might be explained by the recent finding that yeast UPR is inhibited by oxidative stress [65]. With important components of the oxidative stress response missing, yeast UPR could be more efficient in folding of the UPOM-reporter. However, general activation of UPR such as in erj5 [66] and erv25 [67] or hrd1 $\Delta$ mutants where ERAD is affected [68], do not impact on ER-GFP folding [19] (Supplementary Table S1), suggesting a more specific role of stress related UPR for proper reporter folding.

Our screening further revealed unexpected links between ER-GFP, per se a non N-glycosylated protein, and N-glycosylation such as cwh $41 \Delta$ and ost $3 \Delta$ (Supplementary Table S1). CWH41 encodes for $\alpha$-glucosidase I that is responsible for trimming of the outermost glucose of $\mathrm{N}$-glycans within the calnexin-calreticulin cycle, thereby creating a time window before Mns1 and Htm1 mannosidases target the protein for degradation [69]. Ost3 is one out of nine subunits of the yeast OST complex that together with Ost6 determines functionally distinct OST complexes [70]. Ost3 was recently reported to be necessary for N-glycosylation of Pmt2 [71] but no direct evidence of impaired Pmt2 enzymatic activity was obtained in vivo. However, ER-GFP oligomers that are indicative of ER-GFP misfolding [19] were significantly reduced in ost3 $\Delta$ cells suggesting more efficient folding in the absence of Ost3 (Supplementary Figure S2C).

In addition to Pmt1 and Pmt2, the strongest factors identified in the screen directly affecting O-mannosylation of ER-GFP are Psa1 and Bfr1 (Figure 2B).

Psa1 catalyzes biosynthesis of GDP-mannose, the common sugar donor for Dol-P-Man production. Intriguingly, a second enzyme that contributes to GDP-mannose synthesis, the glucose-6-phosphate isomerase Pgi1 (Supplementary Figure S3B), is found at immediate proximity to the screening threshold (Supplementary Table S1), suggesting that GDP-mannose availability might indeed be important for PMT activity. That carbohydrate donor levels affect PMT activity has been also suggested in studies performed in S. cerevisiae [72] and Trichoderma reesei [73] in which manipulation of GDP-mannose levels affects glycosylation. These preliminary data suggest a so far unknown link between carbohydrate metabolism and UPOM.

Bfr1 regulates Pmt1 and Pmt2 translation and therefore impacts on UPOM. Bfr1 is a cytoplasmic protein without any common RNA interacting motifs that was described as a component of polyribosome associated mRNP complexes in S. cerevisiae [38]. Further, Bfr1 mediates localization of certain mRNAs to P-bodies [39] and prevents P-body formation under normal conditions [40] further supporting a function for Bfr1 in mRNA metabolism. P-bodies are dynamic ribonucleoprotein complexes where mRNA storage, translational repression or degradation occurs [74]. Recent RNA binding studies that imply the presence of far more RNA binding domains than known to date [75] in combination with multiple approaches that identify hundreds of different mRNAs interacting with Bfr1 [41,42,76], suggest a role for Bfr1 as an RNA binding protein and translational regulator itself.

In addition to Pmt1 and Pmt2, Bfr1 significantly affects active translation of all PMTs and of additional 322 genes, from which nearly half show reduced translation in absence of Bfr1 (Figure 7A; Supplementary Table S2). Among those we find the sterol reductase Erg4 that catalyzes the final step in ergosterol biosynthesis [77] and that was recently described to be translationally regulated by Bfr1 [78]. We combined our data with Bfr1 interacting transcripts from Lapointe et al. [42] who reported Bfr1 targets to be highly enriched for mRNAs translated at the ER. In this "RNA Tagging" approach, Bfr1 interacting mRNAs were tagged with varying numbers of uridines by the poly(U) polymerase fused to Bfr1, depending on the strength of the interaction. Targets were classified into four groups based on the number of targeted RNAs and the length of the U-tag (class A encloses the strongest interactors). Crossing these datasets shows that Bfr1 controlled targets are enriched in classes A and B, which contain the strongest and most reliable Bfr1 binders. Among class A secretory proteins are Pmt1-4 and Erg4, as well as the OST subunits Ost1, Ost5, and Stt3 that form one out of two subcomplexes 
during OST complex assembly [79]. Given that these subcomplexes are intermediates that protect subunits from degradation, they might play a decisive role in dynamics of OST complex formation and N-glycosylation. In addition, class A secretory proteins harbor several components of ergosterol biosynthesis (Erg3, Erg4, Erg11, and Erg24) and two iron homeostasis genes (Ftr1 and Smf3). This finding is particularly intriguing given the importance of iron for ergosterol biosynthesis and for Ire1 clustering and UPR activation [80]. A summary of all classified targets is available in Supplementary Table S2. Although a more detailed analysis of strong Bfr1 binders will be necessary to define the biological impact of Bfr1 mediated translation, our data strongly suggest a function of Bfr1 as a local translation factor at the ER membrane.

How does cytoplasmic Bfr1 regulate translation at the ER membrane? Our data strongly suggest that Bfr1 is not a prerequisite for PMT transcript recruitment to the ER, in agreement with similar observations for the Bfr1 target Erg4 [78]. For Bfr1 this suggests two possible scenarios: Bfr1 could be targeted to the ER membrane via bound mRNAs as suggested for Erg4 [78] or Bfr1 could be associated with ER bound ribosomes before respective mRNAs reach the ER. It remains a challenging question for the future whether Bfr1 binds to mRNAs before or after their recruitment to the ER.

In a wider context our data together with transcriptomic data from others [15] reveal that ER stress is an important determinant of Pmt1-Pmt2 abundance (Figure 3A,B; Figure 4C), that is additionally controlled on a translational level by Bfr1 (Figure 7). Interestingly Bfr1 is also a target of the UPR (Supplementary Figure S7; [15]) suggesting that the function of Bfr1 is relevant to maintain protein homeostasis in the ER. Maximal Pmt1-Pmt2 expression depends on both, transcriptional activation of Pmt1-Pmt2 under cell stress conditions as well as elevated translation efficiency mediated by Bfr1. The fine-tuned coordination of Pmt1-Pmt2 protein abundance with ER stress further implies that O-mannosylation and protein folding must be balanced to ensure functionality of canonical target proteins and unfolded protein O-mannosylation, the latter being more sensitive to subtle changes of Pmt1-Pmt2 protein levels. Exactly adjusting Pmt1-Pmt2 activity to ER protein load most likely enables O-mannosylation of highly diverse protein substrates without unintentionally interfering with protein folding.

\section{Materials and Methods}

\subsection{Yeast Strains and Culture Conditions}

S. cerevisiae strains used in this study are listed in Table 1. Strains derived from genetic libraries are underlined.

Yeast cultures were grown in yeast extract-peptone-dextrose (YPD) or synthetic defined (SD) medium at $30^{\circ} \mathrm{C}$. For auxotrophic selection corresponding amino acids were excluded from SD medium. For antibiotic-based selection cultures were supplemented with $400 \mu \mathrm{g} / \mathrm{mL}$ geneticin (\#11811-031, Invitrogen; Waltham, MA, USA) or 100 mg/L nourseothricin (\#96736-11-7; Werner BioAgents; Jena-Cospeda, Germany). 
Table 1. S. cerevisiae strains.

\begin{tabular}{|c|c|c|}
\hline Strain & Genotype & Reference/Source \\
\hline BY4741 (wild type) & MATa met15- $\Delta 0$ his3- $\Delta 1$ leu2- $\Delta 0$ ura3- $\Delta 0$ & [81] \\
\hline SEY6210 & $\begin{array}{c}\text { MAT } \alpha \text { lys2-801 his3- } \Delta 200 \text { leu2-3,112 trp1- } \Delta 901 \\
\text { ura3-52 suc2- } \Delta 9\end{array}$ & [82] \\
\hline YMS721 & $\begin{array}{c}\text { MAT } \alpha \text { his } 3 \Delta 1 \text { leu2 } \Delta 0 \text { met } 15 \Delta 0 \text { ura3 } \Delta 0 \\
\text { can1 } \Delta:: \text { STE2pr-spHIS5 lyp } 1 \Delta:: \text { STE3pr-LEU2 }\end{array}$ & [83] \\
\hline JEY05 & YMS721 ho $\Delta::$ ER-GFPf-URA3 & This study \\
\hline JEY06 & YMS721 ho $\Delta::$ ER-GFP-URA3 & This study \\
\hline JCY010 & JEY06 except pmt1 $\triangle:: k a n M X 4$ & This study \\
\hline JCY011 & JEY06 except pmt2 $\Delta:: k a n M X 4$ & This study \\
\hline JCY012 & JEY06 except pmt $4 \Delta:: k a n M X 4$ & This study \\
\hline bfr1 $1 \Delta$ & BY4741 except bfr1 $\Delta:: k a n M X 4$ & Euroscarf \\
\hline psa1DAmP ER-GFP & JEY06 except psa1 $\Delta::$ psa1DAmP & This study \\
\hline bfr1 $\triangle$ ER-GFP & JEY06 except bfr1 $1 \triangle:$ kanMX4 & This study \\
\hline $\operatorname{spf} 1 \Delta$ ER-GFP & JEY06 except spf1 $\triangle:: k a n M X 4$ & This study \\
\hline JCY015 & BY4741 except psa1 $\Delta::$ psa1DAmP & This study \\
\hline JCY016 & JEY06 except bfr1 $\triangle::$ kanMX4 & This study \\
\hline JCY017 & BY4741 except bfr1 $\triangle::$ BFR1-3xHA & This study \\
\hline MLY014 & SEY6210 except PMT2-GAGA-HA3-kanMX6 & This study \\
\hline MLY098 & $\begin{array}{c}\text { SEY6210 except } \\
\text { kITRP1-PGAL1-UBI4-R-PMT2-GAGA-HA3-kanMX6-HA }\end{array}$ & This study \\
\hline JCY034 & MLY098 except bfr1 $1 \Delta::$ URA3 & This study \\
\hline EZY70 & BY4741 except ho $\triangle:: E R-G F P-U R A 3$ & This study \\
\hline EZY77 & ost $3 \Delta$ except ho $\Delta::$ ER-GFP-URA 3 & This study \\
\hline EZY78 & ost6 $\Delta$ except ho $\Delta::$ ER-GFP-URA 3 & This study \\
\hline pmt2 $\triangle$ ER-GFP & pmt2 $\Delta$ except ho $\Delta::$ ER-GFP-URA3 & This study \\
\hline
\end{tabular}

\subsection{Plasmids and Oligonucleotides}

Plasmids used in this study are listed in Table 2. Sequences of oligonucleotides are available on request.

Table 2. Plasmids.

\begin{tabular}{ccc}
\hline Plasmid & Description & Reference/Source \\
\hline pPN014 & ori, CEN/ARS, & This study \\
pWX204 & PTDH3-ER-GFP-3xFLAG-HDEL & \\
& ori, CEN/ARS, & {$[19]$} \\
pWX206 & PTDH3-Kar2SS-ER-GFPf-HDEL, URA3 & \\
pJC01 & PTDH3-Kar2SS-ER-GFP-HDEL, URA3 & {$[19]$} \\
pJC02 & ori, bla, $2 \mu$, PMT2, LEU2 & This study \\
pRS41N & ori, bla, $2 \mu$, PMT2-3xHA, HIS3 & This study \\
pJC09 & ori, CEN/ARS, natNT2 & {$[84]$} \\
pJC10 & ori, CEN/ARS, PMT2, natNT2 & This study \\
pRS415 & ori, CEN/ARS, PMT2-3xHA, natNT2 & This study \\
pJC16 & ori, CEN/ARS, bla, LEU2 & {$[85]$} \\
pUG6 & ori, CEN/ARS, PTDH3-Kar2SS-ER & This study \\
pJH24 & -GFP-HDEL, LEU2 & {$[86]$} \\
& ori, bla, kanMX4 & {$[87]$} \\
\hline
\end{tabular}

To construct plasmid pJC09 for Pmt2 expression the SalI/PstI PMT2 fragment from pVG76 [13] was cloned into pRS425 resulting in pJC01 and the ApaI/SpeI PMT2 fragment from pJC01 was cloned into pRS41N. To construct plasmid pJC10 for Pmt2-3xHA expression the SalI/SmaI PMT2-3xHA fragment from pEZ43 was cloned into pRS423 resulting in pJC02 and the ApaI/SpeI PMT2-3xHA fragment from pJC02 was cloned into pRS41N. To construct pJC16 for Kar2ss-ER-GFP-HDEL expression the NotI/SalI Kar2 ${ }_{S S}-E R-G F P-H D E L$ fragment from pWX206 was subcloned into pRS415. 


\subsection{ER-GFP Screening}

\subsubsection{Automated Library Generation}

Query strain JEY06 expressing ER-GFP was constructed on the synthetic genetic array compatible strain YMS721 [83] and was integrated into yeast deletion [34] and DAmP libraries [35] following synthetic genetic array methodology [88,89]. Mating was performed on 1536-colony format YPD plates using a RoToR bench top colony arrayer (Singer Instruments; Somerset, UK). Resulting diploids were selected for deletion/DAmP libraries and ER-GFP markers KanR and URA3, respectively. Sporulation was induced by transferring cells to nitrogen starvation media for seven days and haploid cells were selected in histidine deficient SD plates to select for spores with an A mating type using canavanine and thialysine (Sigma-Aldrich Chemie; Munich, Germany) against remaining diploids alongside with previously mentioned selection markers.

\subsubsection{High-Throughput Microscopy}

Microscopy screening was performed using an automated fluorescence microscopy setup as previously described [36]. Cells were transferred from agar plates into liquid 384-well polystyrene growth plates using the RoToR arrayer. Liquid cultures were grown over night at $30{ }^{\circ} \mathrm{C}$ in $\mathrm{SD}$ medium in a shacking incubator (LiCONiC Instruments; Mauren, Liechtenstein). A JANUS liquid handler (PerkinElmer; Waltham, MA, USA) connected to the incubator was used to dilute the strains to an $\mathrm{OD}_{600}$ of approximately 0.2 into plates containing the same medium. Plates were incubated at $30{ }^{\circ} \mathrm{C}$ for $4 \mathrm{~h}$ for cells to reach the logarithmic growth phase. Cultures were then transferred by the liquid handler into glass-bottom 384-well microscope plates (Matrical Bioscience; Spokane, WA, USA) coated with Concanavalin A (Sigma-Aldrich Chemie; Munich, Germany). After 20 min, wells were washed twice with SD-Riboflavin complete medium to remove non-adherent cells and to obtain a cell monolayer. Plates were then transferred to the ScanR automated inverted fluorescent microscope system (Olympus; Shinjuku, Japan) using a swap robotic arm (Hamilton; Bonaduz, Switzerland). Images of cells in 384-well plates were recorded in SD-Riboflavin complete medium at $24{ }^{\circ} \mathrm{C}$ at GFP (excitation at $490 / 20 \mathrm{~nm}$, emission at 535/50 nm) channel using a $60 \times$ air lens (NA = 0.9) and with an ORCA-ER charge-coupled device camera (Hamamatsu; Shizuoka, Japan).

\subsubsection{Image Analysis}

Analysis of ER-GFP intensity was performed using the Olympus ScanR analysis software. Images were preprocessed by background subtraction and segmentation was done with the brightfield images and a series of shape conditions were applied as filters. The median GFP intensity for each strain was measured from the remaining objects for each strain. Dead cells appeared as high fluorescent outlier values and were removed with the ScanR software in an automated manner. Strains with insufficient number of detected objects $(<25)$ as well as contaminated strains were removed from the analysis.

\subsection{Real-Time Quantitative Polymerase Chain Reaction (RT-qPCR)}

\subsubsection{Total RNA Isolation}

For total RNA isolation cells were grown to mid-log phase at $30^{\circ} \mathrm{C}$. Ice-cold $\mathrm{NaN}_{3}$ was added to the culture to a final concentration of $100-200 \mathrm{mM}$ and $5 \mathrm{OD}_{600}$ units were harvested by centrifugation for $5 \mathrm{~min}$ at $3000 \times \mathrm{g}$. Total RNA was isolated using the Universal RNA Purification Kit (Roboklon; Berlin, Germany) according to manufacturer's instructions. For spheroplast generation prior to lysis lyticase (\#L2524 Sigma-Aldrich Chemie; Munich, Germany) was added to the corresponding buffer. When indicated during the protocol RNase-free DNase (\#M6101, Promega; Madison, WI, USA) was added to the RNA binding columns and incubated at RT for $10 \mathrm{~min}$. For representative sets of samples RNA integrity was verified by agarose gel electrophoresis. 


\subsection{2. cDNA Synthesis}

Two $\mu \mathrm{g}$ of total RNA were reverse transcribed into cDNA using the RevertAid First Strand cDNA Synthesis Kit (\#K1622, Thermo Fisher Scientific, Bonn, Germany) with Oligo(dT)18 primers following manufacturer's instructions.

\subsubsection{Real-Time Quantitative Polymerase Chain Reaction (RT-qPCR)}

RT-qPCR was performed on the Rotor-Gene Q (Qiagen) using the qPCRBIO SyGreen Mix Lo-ROX (\#PB20.11, PCR Biosystems, London, UK). PCR reactions were performed in a final volume of $12.5 \mu \mathrm{L}$ containing $\times \mu \mathrm{L}$ of 1:20 cDNA dilution and $0.4 \mathrm{mM}$ of respective oligonucleotides. As technical replicates and for determination of RT-qPCR efficiency 1:100 and 1:1000 cDNA dilutions were included. Only RT-PCR reactions with efficiencies ranging from 0.9 to 1.1 were further analyzed. For calculation of either relative gene expression or fold-change in gene expression, both standard curve-based and $2-\Delta \Delta \mathrm{Ct}$ methods were used. Statistical analysis was performed on three independent biological replicates. Statistical significance was assessed as individually stated.

\subsection{Preparation of Cell Extracts and Membranes}

For cell extract preparation cells were grown to mid-log phase at $30^{\circ} \mathrm{C}$. For end-point analyses or time course experiments ice-cold $\mathrm{NaN}_{3}$ was added to the culture to a final concentration of $100-200 \mathrm{mM}$ and 10 or $20 \mathrm{OD}_{600}$ units were harvested by centrifugation for $5 \mathrm{~min}$ at $3000 \times g$. Cells were washed and resuspended in 50 or $100 \mu \mathrm{L}$ breaking buffer $(50 \mathrm{mM}$ Tris- $\mathrm{HCl} \mathrm{pH} 7.4$, $5 \mathrm{mM} \mathrm{MgCl}_{2}$ ) supplemented with protease inhibitors (1 mM PMSF, $1 \mathrm{mM}$ benzamidine, $0.25 \mathrm{mM}$ 1-chloro-3-tosylamido-7-amino-2-heptanone, 50 mg/mL 1-1-tosylamido-2-phenylethyl chloromethyl ketone, $10 \mu \mathrm{g} / \mathrm{mL}$ antipain, $1 \mu \mathrm{g} / \mathrm{mL}$ leupeptin and $1 \mu \mathrm{g} / \mathrm{mL}$ pepstatin). Cell suspension was transferred to a tube with glass beads (ø 0.25-0.5 mm, \#A553.1, Roth; Karlsruhe, Germany) and cells were subjected to mechanic lysis using the Hybaid RiboLyser (Thermo Fisher Scientific; Bonn, Germany) in four rounds of $25 \mathrm{~s}$ at 4.5 speed level. For cell extract preparation cell debris was pelleted by centrifugation for $5 \mathrm{~min}$ at $1500 \times \mathrm{g}$. For membrane preparation total cell extracts were centrifuged for $1 \mathrm{~h}$ at $20,000 \times \mathrm{g}$. Membrane pellets were resuspended with a $0.3 \mathrm{~mm}$ syringe in equivalent volume of membrane buffer (20 mM Tris-HCl pH 8.0, 10 mM EDTA pH 8.0, 15\% (v/v) glycerol) supplemented with protease inhibitors.

\subsection{Flag-Tag Immunoprecipitation}

For immunoprecipitation $20 \mathrm{OD}_{600}$ units of cells grown to mid-log phase were subjected to membrane preparation with the following modifications: 1 . Total cell extracts were centrifuged for $30 \mathrm{~min}$ at maximum speed (approximately $30,000 \times g$ ). 2 . Membrane buffer was supplemented with $1 \%$ Triton X-100 and samples were placed on a rotator mixer for $10 \mathrm{~min}$ at RT. 3. Samples were diluted 1:4 in TBS supplemented with $1 \mathrm{mM}$ PMSF and centrifuged for $15 \mathrm{~min}$ at 20,000 $\mathrm{g}$ to remove insoluble material. For Flag-tag immunoprecipitation samples were incubated with $100 \mu \mathrm{L}$ of anti-FLAG M2 magnetic beads (\#M8823, Sigma-Aldrich Chemie; Munich, Germany) for $4 \mathrm{~h}$ at $4{ }^{\circ} \mathrm{C}$. The bound fraction was eluted by addition of FLAG peptide to a final concentration of $0.3 \mu \mathrm{g} / \mu \mathrm{L}$ and further rotation for $1 \mathrm{~h}$ at $4{ }^{\circ} \mathrm{C}$. Demannosylation of ER-GFP was performed with $\alpha 1-2,3,6$ mannosidase (\#9025-42-7, Sigma-Aldrich Chemie; Munich, Germany) according to manufacturer's instructions.

\subsection{Cycloheximide Chase Experiments}

Cells were grown under standard conditions in YPD medium and were initially sampled for time point zero. Cycloheximide was immediately added to a final concentration of 100 to $200 \mu \mathrm{M}$ and equal amounts of cells were sampled at indicated time points. Sampled cells were treated with $\mathrm{NaN}_{3}$ to a final concentration of $20 \mathrm{mM}$ to stop the chase and were kept on ice until the last sample was collected. Total cell extracts were analyzed via Western blot. 


\subsection{Western Blot Analysis}

Protein samples were denatured in $1 \times$ SDS-sample buffer for $10 \mathrm{~min}$ at $70{ }^{\circ} \mathrm{C}$ and resolved in $12 \%$ sodium dodecyl sulfate polyacrylamide (SDS PAA) gels. Proteins were transferred to nitrocellulose membranes and visualized by enhanced chemiluminescence using ECL Prime Western Blotting Detection Reagent (\#RPN2232, GE Healthcare; Chicago, IL, USA) and imager ImageQuant LAS 4000 (GE Healthcare; Chicago, IL, USA). Primary and secondary antibodies used in this study are summarized in Table 3.

Table 3. Antibodies.

\begin{tabular}{ccc}
\hline Name & Description & Reference/Source \\
\hline$\alpha$ Pmt1 & rabbit; $1: 2500$ & {$[3]$} \\
$\alpha$ Pmt2 & rabbit; $1: 2500$ & {$[90]$} \\
$\alpha$ Pmt 4 & rabbit; $1: 250$ & {$[13]$} \\
$\alpha$ Sec61 & rabbit; $1: 2500$ & {$[91]$} \\
$\alpha$ HA & mouse; $1: 10,000$ & \#MMS-101R; Covance; Princeton, NJ, USA \\
$\alpha$ Gas1 & rabbit; $1: 2500$ & {$[92]$} \\
$\alpha$ Wbp1 & rabbit; $1: 2500$ & {$[93]$} \\
$\alpha$ Kar2 & rabbit; $1: 500$ & \\
$\alpha$ Ost3 & rabbit; $1: 1000$ & Gift from M. Aebi \\
$\alpha$ G6PDH & rabbit; $1: 5000$ & \#A9521; Sigma-Aldrich Chemie; Munich, Germany \\
$\alpha$ GFP & rabbit; $1: 2500$ & \#A6455; Thermo Fisher Scientific; Waltham, MA, USA \\
$\alpha$ Rpl5 & rabbit; $1: 7000$ & Gift from E. Hurt \\
$\alpha$ mouseHRP & rabbit; $1: 10,000$ & \#A9044; Sigma-Aldrich; Munich, Germany \\
$\alpha$ rabbitHRP & goat; $1: 10,000$ & \#A6154; Sigma-Aldrich; Munich, Germany \\
\hline
\end{tabular}

\subsection{Cell Fractionation Coupled to RNA Preparation}

Both methods are adapted from [52,94].

\subsubsection{Cell Fractionation by One Step Ultracentrifugation}

Cells grown to mid-log phase were treated with $100 \mu \mathrm{g} / \mathrm{mL}$ cycloheximide for $15 \mathrm{~min}$ before harvest. Cells equivalent to $20 \mathrm{OD}_{600}$ units were harvested by centrifugation for $5 \mathrm{~min}$ at $3000 \times g$, washed with ice-cold SK buffer (1.2 M sorbitol, $0.1 \mathrm{M} \mathrm{KPO}_{4} \mathrm{pH} 7.5,100 \mu \mathrm{g} / \mathrm{mL}$ cycloheximide) and incubated for $5 \mathrm{~min}$ on ice. Cells were pelleted by centrifugation for $3 \mathrm{~min}$ at $500 \times \mathrm{g}$ and were resuspended in $250 \mu \mathrm{L}$ BRS buffer ( $50 \mathrm{mM}$ Tris- $\mathrm{HCl} \mathrm{pH}$ 7.6, $150 \mathrm{mM} \mathrm{NaCl}, 250 \mathrm{mM}$ sorbitol, $30 \mathrm{mM} \mathrm{MgCl}$, $100 \mu \mathrm{g} / \mathrm{mL}$ cycloheximide, $200 \mathrm{U} / \mathrm{mL}$ RNasin ribonuclease inhibitor (\#N2511, Promega; Madison, WI, USA)) supplemented with protease inhibitors as described for preparation of cell extracts and membranes. Mechanical lysis was performed with glass beads using the Hybaid RiboLyser in five rounds of $35 \mathrm{~s}$ at 4.5 speed level. For cell extract preparation cell debris was pelleted by centrifugation for $10 \mathrm{~min}$ at $1000 \times g .200 \mu \mathrm{L}$ of cell extract were fractionated by ultracentrifugation at $48,000 \times g$ resulting in a soluble fraction and a membrane pellet. Membrane pellets were resuspended in 400-500 $\mu \mathrm{L}$ BMRS buffer (BRS buffer with $80 \mathrm{U} / \mathrm{mL}$ RNasin ribonuclease inhibitor) with a $0.3 \mathrm{~mm}$ syringe and ultracentrifugation was repeated. Total RNA was prepared from $100 \mu \mathrm{L}$ of soluble and membrane fractions using the Universal RNA Purification Kit (Roboklon; Berlin, Germany) according to manufacturer's instructions.

\subsubsection{Cell Fractionation by Sucrose Step Gradient Centrifugation}

Mid-log phase grown cells equivalent to $300 \mathrm{OD}_{600}$ units were harvested by centrifugation for $5 \mathrm{~min}$ at $3000 \times g$, washed with ice-cold SK buffer and incubated for $5 \mathrm{~min}$ on ice. Cells were pelleted by

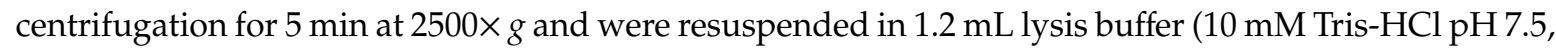
$0.25 \mathrm{M}$ sucrose, $30 \mathrm{mM} \mathrm{MgCl} 2,1 \mathrm{mM}$ DTT, $100 \mu \mathrm{g} / \mathrm{mL}$ cycloheximide, $200 \mathrm{U} / \mathrm{mL}$ RNasin ribonuclease inhibitor) supplemented with protease inhibitors as described for preparation of cell extracts and membranes. Mechanical lysis was performed with glass beads using the Hybaid RiboLyser in four 
rounds of $45 \mathrm{~s}$ at 4.5 speed level. For cell extract preparation cell debris was pelleted by centrifugation for $10 \mathrm{~min}$ at $1000 \times \mathrm{g}$. Nine hundred microliters of cell extract were diluted with lysis buffer to $2 \mathrm{~mL}$ final volume. For preparation of a discontinuous sucrose gradient $3 \mathrm{~mL}$ of a $1.5 \mathrm{M}$ and $1.2 \mathrm{M}$ sucrose buffer were added on top of a $2 \mathrm{M}$ sucrose cushion. Total cell extract was loaded on top of the gradient and centrifugation was performed for $2.5 \mathrm{~h}$ at $232,000 \times \mathrm{g}$. The gradient was manually fractionated in $0.5 \mathrm{~mL}$ fractions and protein content of selected fractions was analyzed by SDS-PAGE. Total RNA was prepared from $300 \mu \mathrm{L}$ of selected fractions using the Universal RNA Purification Kit (Roboklon; Berlin, Germany) according to manufacturer's instructions. Semi-quantitative PCR was performed using the DreamTaq Green PCR master mix (\#K1081, Thermo Fisher Scientific; Waltham, MA, USA) according to manufacturer's instructions. PCR was performed with $1 \mu \mathrm{L}$ of a 1:20 dilution of cDNA in 23 or 25 cycles with a final primer concentration of $0.5 \mu \mathrm{M}$ in a $20 \mu \mathrm{L}$ reaction.

\subsection{Flow Cytometry}

Cells expressing ER-GFP were grown to mid-log phase in the corresponding medium at $30^{\circ} \mathrm{C}$. FACS analysis of 20,000 cells was performed using the cell analyzer BD FACSCanto ${ }^{\mathrm{TM}}$ (BD Biosciences; Heidelberg, Germany) in collaboration with the Flow Cytometry and FACS Core Facility (ZMBH, Heidelberg University; Heidelberg, Germany).

\subsection{Fluorescence Microscopy}

Cells expressing ER-GFP were grown to mid-log phase in the corresponding medium at $30^{\circ} \mathrm{C}$ and microscopy was performed on standard glass plates using an LSM510-META confocal laser scanning microscope (Carl Zeiss; Jena, Germany) with $\times 100$ or $\times 40$ Plan Apochromat objectives. GFP signal (excitation $488 \mathrm{~nm}, \mathrm{Ar}^{+}$laser) was detected by using a bandpass emission filter for $505-530 \mathrm{~nm}$.

\subsection{Ribosome Profiling}

\subsubsection{Sample Preparation}

Wild type and $b f r 1 \Delta$ cells were grown to mid-log phase at $30{ }^{\circ} \mathrm{C}$ and approximately $150 \mathrm{OD}_{600}$ units were harvested using rapid filtration and flash freezing in liquid nitrogen. Frozen cell pellets were mixed with $750 \mu \mathrm{L}$ of frozen lysis buffer droplets $(20 \mathrm{mM}$ Tris- $\mathrm{HCl} \mathrm{pH} 8,140 \mathrm{mM} \mathrm{KCl}, 10 \mathrm{mM}$ $\mathrm{MgCl}_{2}, 20 \%(v / v) \mathrm{NP}-40,100 \mu \mathrm{g} / \mathrm{mL}$ cycloheximide, $1 \times$ EDTA-free protease inhibitor cocktail (Roche; Basel, Switzerland), $0.02 \mathrm{U} / \mu \mathrm{L}$ DNase I (Roche; Basel, Switzerland), $40 \mu \mathrm{g} / \mathrm{mL}$ bestatin) and a metal ball in pre-chilled metal jars and lysed by mixer milling 2 min at $30 \mathrm{~Hz}$ (MM400, Retsch; Haan, Germany). Cell lysates were thawed in a $30^{\circ} \mathrm{C}$ water bath, transferred to low binding tubes and RNA concentration was determined by Nanodrop. Lysates were next subjected to RNase I digestion (10 U of RNase I per $\mathrm{Abs}_{260}$ unit) for $30 \mathrm{~min}$ at $4{ }^{\circ} \mathrm{C}$, the reaction was stopped by adding $10 \mu \mathrm{L}$ of SUPERase-In RNase inhibitor (\#LSAM2694, Invitrogen; Waltham, MA, USA) and lysates were cleared by $5 \mathrm{~min}$ centrifugation at $20,000 \times g$.

Total ribosomes were collected by sucrose cushion centrifugation. Maximum of $400 \mu \mathrm{L}$ of cleared lysate were loaded onto $800 \mu \mathrm{L}$ of sucrose cushion buffer $(20 \mathrm{mM}$ Tris- $\mathrm{HCl}$ pH 8, $140 \mathrm{mM} \mathrm{KCl}, 10 \mathrm{mM}$ $\mathrm{MgCl}_{2}, 100 \mu \mathrm{g} / \mathrm{mL}$ cycloheximide, $1 \times$ EDTA-free protease inhibitor cocktail (Roche; Basel, Switzerland), $25 \%(v / v)$ sucrose) in sucrose cushion tubes and centrifuged for $90 \mathrm{~min}$ at $75,000 \mathrm{rpm}$ and $4{ }^{\circ} \mathrm{C}$ in a TLA120-rotor (Beckman; Indianapolis, IN, USA). Pellets were resuspended in lysis buffer by continuous agitation at $4{ }^{\circ} \mathrm{C}$ and transferred to non-stick tubes.

\subsubsection{Ribosome-Protected Footprint mRNA Extraction}

mRNA footprints were extracted from processed samples by phenol-chloroform extraction. In brief, ribosome pellets were brought to a final volume of $700 \mu \mathrm{L}$ with lysis buffer and mixed with $40 \mu \mathrm{L}$ $20 \%(v / v)$ SDS to precipitate the protein content. Seven hundred and fifty microliters of pre-warmed $\left(65^{\circ} \mathrm{C}\right)$ acid phenol was added and samples were incubated for $5 \mathrm{~min}$ at $65^{\circ} \mathrm{C}$ and $1400 \mathrm{rpm}$ shaking; 
and chilled for $5 \mathrm{~min}$ on ice. Next, samples were centrifuged for $2 \mathrm{~min}$ at 20,000 $\mathrm{g}$ and the aqueous phase was transferred to a new tube. Seven hundred microliters of hot phenol were again added and samples were incubated $5 \mathrm{~min}$ at room temperature with occasional vortexing. Six hundred microliters of chloroform were added and mixed by vortexing. Samples were centrifuged for $1 \mathrm{~min}$ at 20,000 $\mathrm{g}$ and the aqueous phase was transferred to a new tube. To precipitate nucleic acids, $\sim 650 \mu \mathrm{L}$ of the sample were mixed with 1:9 equivalence volume of $3 \mathrm{M} \mathrm{NaOAc} \mathrm{pH} 5.5,1$ equivalence volume of isopropanol and $2 \mu \mathrm{L}$ of Glycoblue, mixed by vortexing and chilled overnight at $-80^{\circ} \mathrm{C}$.

Next, RNA samples were centrifuged for $2 \mathrm{~h}$ at $20,000 \times g$ and $4{ }^{\circ} \mathrm{C}$ and the pellet was washed with $750 \mu \mathrm{L}$ ice-cold $70 \%$ ethanol. Centrifugation was repeated for $2 \mathrm{~min}$ and the pellet was dried for $2 \mathrm{~min}$ at $65^{\circ} \mathrm{C}$. Pellets were finally resuspended in $20-50 \mu \mathrm{L}$ of $10 \mathrm{mM}$ Tris- $\mathrm{HCl} \mathrm{pH} 7$.

RNA enrichment was verified by Bioanalyzer RNA Nanochip (Agilent; Santa Clara, CA, USA) and total RNA concentration was determined by Nanodrop after diluting RNA samples in water and $10 \mathrm{mM}$ Tris- $\mathrm{HCl} \mathrm{pH}$ 7, respectively.

\subsubsection{Deep Sequencing Library Preparation}

Total translatome analysis was performed according to [95] with some modifications. RNA samples were heated at $80^{\circ} \mathrm{C}$ for $2 \mathrm{~min}$ and $40-50 \mathrm{mg}$ of RNA were loaded onto $15 \%$ TBE-Urea polyacrylamide gels (Invitrogen; Waltham, MA, USA) in 1× TBE (Thermo Fisher Scientific; Waltham, MA, USA) and run for $65 \mathrm{~min}$ at $200 \mathrm{~V}$. Gels were stained for $20 \mathrm{~min}$ with SYBR gold (Invitrogen; Waltham, MA, USA) and ribosome footprints were recovered from the gels by excising sections of 21 to 33 nucleotide size. Gel pieces were placed into $0.5 \mathrm{~mL}$ gel breaker tubes and centrifuged for $3 \mathrm{~min}$ at $20,000 \times \mathrm{g}$. Remaining pieces were transferred to a fresh $1.5 \mathrm{~mL}$ tube, resuspended with $10 \mathrm{mM}$ Tris- $\mathrm{HCl} \mathrm{pH} 7$ and incubated for $15 \mathrm{~min}$ at $70{ }^{\circ} \mathrm{C}$ in a thermomixer with maximum shaking. The gel slurry was then transferred to a Spin- $X$ cellulose acetate column (\#60702, Thermo Fisher Scientific; Waltham, MA, USA) and centrifuged for $3 \mathrm{~min}$ at 20,000 $\mathrm{g}$. Flow through was transferred to a fresh pre-cooled non-stick tube on ice. Nucleic acids samples were precipitated as described in the latter section. Next, RNA samples were centrifuged for $2 \mathrm{~h}$ at $20,000 \times g$ and $4{ }^{\circ} \mathrm{C}$ and the pellet was washed with $750 \mu \mathrm{L}$ ice-cold $70 \%$ ethanol. Centrifugation was repeated for $2 \mathrm{~min}$ and the pellet was dried for $2 \mathrm{~min}$ at $65^{\circ} \mathrm{C}$. Pellets were finally resuspended in $15 \mu \mathrm{L}$ of $10 \mathrm{mM}$ Tris- $\mathrm{HCl} \mathrm{pH} 7$ and transferred to a fresh non-stick tube.

To dephosphorylate $3^{\prime}$ ends of ribosome footprints, a master mix was prepared containing $2 \mu \mathrm{L}$ $10 \times$ T4 polynucleotide kinase buffer without ATP (NEB) and $1 \mu \mathrm{L}$ murine RNase inhibitor per sample and $3 \mu \mathrm{L}$ were added to each sample together with $2 \mu \mathrm{L}$ truncated T4 polynucleotide kinase (\#M0201, NEB; Frankfurt/Main, Germany). Samples were incubated for $2 \mathrm{~h}$ at $37^{\circ} \mathrm{C}$ and the enzyme was deactivated after the reaction by $10 \mathrm{~min}$ incubation at $75^{\circ} \mathrm{C}$. At this point, nucleic acids were again precipitated as previously indicated. Samples were centrifuged for $1 \mathrm{~h}$ at $20,000 \times g$ and $4{ }^{\circ} \mathrm{C}$ and RNA pellets were washed with $70 \%$ ethanol and resuspended in $15 \mu \mathrm{L}$ of $10 \mathrm{mM}$ Tris- $\mathrm{HCl} \mathrm{pH} 7$ and transferred to a fresh non-stick tube as previously indicated. RNA concentration was measured by Bioanalyzer RNA Nanochip (Agilent; Santa Clara, CA, USA) and by nanodrop after diluting RNA samples in water and $10 \mathrm{mM}$ Tris- $\mathrm{HCl} \mathrm{pH}$ 7, respectively.

For $3^{\prime} \mathrm{L} 1$ linker ligation, samples were diluted to a final RNA concentration of $10 \mathrm{pmol}$ in $10 \mu \mathrm{L}$ of $10 \mathrm{mM}$ Tris- $\mathrm{HCl} \mathrm{pH} 7$ and denatured for $2 \mathrm{~min}$ at $80^{\circ} \mathrm{C}$. A master mix was prepared containing $16 \mu \mathrm{L} \mathrm{50 \%}$ sterile filtered PEG MW 8000, $4 \mu \mathrm{L}$ DMSO, $4 \mu \mathrm{L} 10 \times$ T4 RNA Ligase 2 buffer and $2 \mu \mathrm{L}$ murine RNase inhibitor. Master mix was added to each sample together with $1 \mu \mathrm{L}$ truncated T4 RNA Ligase 2 (\#M0239, NEB; Frankfurt/Main, Germany). Ligation was carried out for $2 \mathrm{~h}$ at $23^{\circ} \mathrm{C}$ and nucleic acids were precipitated, RNA pellets were washed with $70 \%$ ethanol as previously indicated and resuspended in $6 \mu \mathrm{L}$ of $10 \mathrm{mM}$ Tris- $\mathrm{HCl} \mathrm{pH} \mathrm{7.} 3^{\prime}$-linked footprints were denatured at $80^{\circ} \mathrm{C}$ for 2 min and purified on 10\% TBE-Urea polyacrylamide gels (Invitrogen; Waltham, MA, USA) in 1× TBE (Thermo Fisher Scientific; Waltham, MA, USA) run for $50 \mathrm{~min}$ at $200 \mathrm{~V}$. Gels were stained for 20 min with SYBR gold (Invitrogen; Waltham, MA, USA) and 3'-linked footprints were recovered 
from the gels by excising sections of 64 nucleotide size (footprint + L1). Similar to the previous in-gel purification, gel pieces were placed into $0.5 \mathrm{~mL}$ gel breaker tubes and centrifuged for $5 \mathrm{~min}$ at $20,000 \times g$ Remaining pieces were transferred to a fresh $1.5 \mathrm{~mL}$ tube, resuspended with $10 \mathrm{mM}$ Tris- $\mathrm{HCl} \mathrm{pH} 7$ and incubated for $15 \mathrm{~min}$ at $70{ }^{\circ} \mathrm{C}$ in a thermomixer with maximum shaking. The gel slurry was then transferred to a Spin-X cellulose acetate column (\#60702, Thermo Fisher Scientific; Waltham, MA, USA) and centrifuged for $3 \mathrm{~min}$ at $20,000 \times \mathrm{g}$. Flow through was transferred to a fresh pre-cooled non-stick tube on ice, nucleic acids were precipitated, RNA pellets washed with $70 \%$ ethanol as previously indicated and resuspended in $6 \mu \mathrm{L}$ of $10 \mathrm{mM}$ Tris- $\mathrm{HCl} \mathrm{pH} 7$.

To generate ssDNA 3'-linked footprint fragments were reverse transcribed. A master mix containing $1 \mu \mathrm{L} 10 \mathrm{mM}$ dNTP mix, $1 \mu \mathrm{L} 25 \mu \mathrm{M}$ Linker L1'L20 and $1.5 \mu \mathrm{L}$ DEPC $\mathrm{H}_{2} \mathrm{O}$ was prepared and added to the samples. Samples were incubated for $5 \mathrm{~min}$ at $65{ }^{\circ} \mathrm{C}$ and $4 \mathrm{~mL} 5 \times$ FSB buffer (Invitrogen; Waltham, MA, USA), $1 \mathrm{~mL}$ murine RNase inhibitor, $1 \mathrm{~mL} 0.1 \mathrm{M}$ DTT (Invitrogen; Waltham, MA, USA) and $1 \mathrm{~mL}$ Superscript III (Invitrogen; Waltham, MA, USA) were added. Reverse transcription was performed for $30 \mathrm{~min}$ at $50{ }^{\circ} \mathrm{C}$ and the reaction was quenched by adding $2.3 \mathrm{~mL} 1 \mathrm{~N} \mathrm{NaOH}$ and further incubating for $15 \mathrm{~min}$ at $95^{\circ} \mathrm{C}$. Samples were denatured for $2 \mathrm{~min}$ at $70{ }^{\circ} \mathrm{C}$ and run on a $10 \%$ TBE-Urea polyacrylamide gel for $70 \mathrm{~min}$ at $200 \mathrm{~V}$. Gels were stained as described before, desired bands were excised and nucleic acids were extracted as mentioned earlier except remaining gel pieces were mixed with $0.5 \mathrm{~mL} 10 \mathrm{mM}$ Tris- $\mathrm{HCl} \mathrm{pH}$ 8. Nucleic acids were precipitated by adding 1:16 equivalence volume of $5 \mathrm{M} \mathrm{NaCl}$ and 1:500 equivalence volume of $0.5 \mathrm{M}$ EDTA together with 1 equivalence volume of isopropanol and $2 \mu \mathrm{L}$ of Glycoblue. Precipitation was performed at $-20{ }^{\circ} \mathrm{C}$ overnight and pellets were washed with $70 \%$ ethanol and resuspended in $15 \mu \mathrm{L} 10 \mathrm{mM}$ Tris- $\mathrm{HCl} \mathrm{pH} 8$ as previously described.

To circularize ssDNA a master mix containing $2 \mu \mathrm{L}$ 10× CircLigase buffer, $1 \mu \mathrm{L} 1 \mathrm{mM}$ ATP, $1 \mu \mathrm{L}$ $50 \mathrm{mM} \mathrm{MnCl}{ }_{2}$ was added to the samples together with $1 \mu \mathrm{L}$ CircLigase (EPICENTRE). The reaction was carried out for $1 \mathrm{~h}$ at $60^{\circ} \mathrm{C}$ and the enzyme was inactivated by further incubation for $10 \mathrm{~min}$ at $80^{\circ} \mathrm{C} .1 \mu \mathrm{L}$ of circularized ssDNA was used as a template for 4 technical replicates of Phusion-based PCR using the following mix and PCR program: PCR mix (62.6 $\mu \mathrm{L} \mathrm{DEPC} \mathrm{H}_{2} 0,16.7 \mu \mathrm{L} 5 \times \mathrm{HF}$ buffer, $1.7 \mu \mathrm{L} 10 \mathrm{mM}$ dNTPs, $0.4 \mu \mathrm{L} 100 \mathrm{mM}$ barcoding primer, $0.4 \mu \mathrm{L} 100 \mathrm{mM}$ PCR primer L1', $0.8 \mu \mathrm{L}$ Phusion polymerase), PCR program (Initial denaturation: $98^{\circ} \mathrm{C}, 30 \mathrm{~s}$, (Denaturation; $98^{\circ} \mathrm{C}, 10 \mathrm{~s}$, Annealing: $60{ }^{\circ} \mathrm{C}, 10 \mathrm{~s}$, Elongation: $\left.72{ }^{\circ} \mathrm{C}, 5 \mathrm{~s}\right) \times 10$ cycles). One tube was removed from the PCR reaction after cycles $7,8,9$, and 10. Samples were run on a $8 \%$ TBE polyacrylamide gel (Invitrogen; Waltham, MA, USA) in $1 \times$ TBE (Thermo Fisher Scientific; Waltham, MA, USA) for 55 min at 180 V. Gels were stained as mentioned before, desired bands from each PCR reaction were excised and DNA was extracted as described before for the ssDNA samples. Size distribution of DNA fragments was determined by Bioanalyzer, concentration was determined by Qubit (\#Q32852, Invitrogen; Waltham, MA, USA) and samples were sequenced on a HiSeq (Illumina; San Diego, CA, USA).

Sequenced reads were processed as described previously [96] using standard analysis tools (Bowtie2, Tophat2) and python scripts adapted to S. cerevisiae. For each read, the P-site position was determined using a 5' offset of 15 nucleotides. Only reads with a length of 25-35 nucleotides were used. Reads with $P$ sites falling within an annotated ORF were counted, differential expression analysis was performed with DESeq2 [97] and false discovery rate was controlled using the Benjamini-Hochberg procedure [98] with independent hypothesis weighting [99].

Supplementary Materials: Supplementary materials can be found at http://www.mdpi.com/1422-0067/20/24/ 6220/s1. Supplementary Figures; Supplementary Table S1. UPOM screening results; Supplementary Table S2. Ribosome profiling.

Author Contributions: Conceptualization, J.C.-B., G.K., M.S. and S.S.; Data curation, J.C.-B., I.K. (Ilgin Kotan), L.G., D.B. and E.Z.; Formal analysis, J.C.-B., N.R., I.K. (Ilgin Kotan), L.G., D.B. and I.K. (Ilia Kats); Funding acquisition, B.B., M.S. and S.S.; Methodology, J.C.-B., I.K. (Ilgin Kotan), L.G., G.K., M.S. and S.S.; Project administration, S.S.; Resources, G.K., B.B., M.S. and S.S.; Software, I.K. (Ilia Kats) and G.K.; Supervision, G.K., M.S. and S.S.; Validation, J.C.-B., N.R., G.K., M.S. and S.S.; Visualization, N.R. and I.K. (Ilia Kats); Writing-original draft, N.R., S.S. and J.C.-B.; Writing-review and editing, G.K. and M.S. 
Funding: This work was supported by the Deutsche Forschungsgemeinschaft, Sonderforschungsbereich 1036, project 11 (to S.S.) and project 08 (to B.B.). Work in the M. Schuldiner lab is supported by an Israeli science foundation grant (760/17) and a Minerva foundation grant. MS is an incumbent of the Dr. Gilbert Omenn and Martha Darling Professorial Chair in Molecular Genetics.

Acknowledgments: We are grateful to Davis Ng for providing plasmids pWX204 and pWX206. We thank Anke Metschies and Silvia Chuartzman for excellent technical assistance, Sven Klassa for his help on the analysis of $p s a 1^{D A m p}$ and $p g i 1^{D A m p}$ mutants and Jakob Engel for generating yeast strains JEY05 and JEY06.

Conflicts of Interest: The authors declare no conflict of interest.

\section{Abbreviations}

ER

UPOM

GFP

Bfr1

Dol-P-Man

PMT

UPR

ERAD

MFI

HOG pathway

OST

RPM

FDR

YPD medium

SD medium

RT-qPCR

rep

TCL

N.s.

NA endoplasmic reticulum

unfolded protein O-mannosylation

green fluorescent protein

brefeldin A resistance factor 1

Dol-P-mannose

protein O-mannosyltransferase

unfolded protein response

ER associated degradation

median fluorescence intensity

high osmolarity glycerol pathway

oligosaccharyl transferase

reads per million mapped reads

false discovery rate

yeast extract-peptone-dextrose medium

synthetic defined medium

real-time quantitative polymerase chain reaction

replicate

total cell lysate

not significant

not assigned

\section{References}

1. Spiro, R.G. Protein glycosylation: Nature, distribution, enzymatic formation, and disease implications of glycopeptide bonds. Glycobiology 2002, 12, 43r-56r. [CrossRef] [PubMed]

2. Neubert, P.; Strahl, S. Protein O-mannosylation in the early secretory pathway. Curr. Opin. Cell Biol. 2016, 41, 100-108. [CrossRef] [PubMed]

3. Strahl-Bolsinger, S.; Tanner, W. Protein O-glycosylation in Saccharomyces cerevisiae. Purification and characterization of the dolichyl-phosphate-D-mannose-protein O-D-mannosyltransferase. Eur. J. Biochem. 1991, 196, 185-190. [CrossRef] [PubMed]

4. Lussier, M.; Gentzsch, M.; Sdicu, A.M.; Bussey, H.; Tanner, W. Protein O-glycosylation in yeast. The PMT2 gene specifies a second protein O-mannosyltransferase that functions in addition to the PMT1-encoded activity. J. Biol. Chem. 1995, 270, 2770-2775. [CrossRef] [PubMed]

5. Immervoll, T.; Gentzsch, M.; Tanner, W. PMT3 and PMT4, two new members of the protein-O-mannosyltransferase gene family of Saccharomyces cerevisiae. Yeast 1995, 11, 1345-1351. [CrossRef]

6. Jurado, L.A.; Coloma, A.; Cruces, J. Identification of a human homolog of the Drosophila rotated abdomen gene (POMT1) encoding a putative protein O-mannosyl-transferase, and assignment to human chromosome 9q34.1. Genomics 1999, 58, 171-180. [CrossRef]

7. Willer, T.; Amselgruber, W.; Deutzmann, R.; Strahl, S. Characterization of POMT2, a novel member of the PMT protein O-mannosyltransferase family specifically localized to the acrosome of mammalian spermatids. Glycobiology 2002, 12, 771-783. [CrossRef]

8. Brancaccio, A. A molecular overview of the primary dystroglycanopathies. J. Cell. Mol. Med. 2019, 23, 3058-3062. [CrossRef] 
9. Carvalho, S.; Reis, C.A.; Pinho, S.S. Cadherins glycans in cancer: Sweet players in a bitter process. Trends Cancer 2016, 2, 519-531. [CrossRef]

10. Kumari, K.; Das, B.; Adhya, A.K.; Rath, A.K.; Mishra, S.K. Genome-wide expression analysis reveals six contravened targets of EZH2 associated with breast cancer patient survival. Sci. Rep. 2019, 9, 1974. [CrossRef]

11. Loibl, M.; Wunderle, L.; Hutzler, J.; Schulz, B.L.; Aebi, M.; Strahl, S. Protein O-mannosyltransferases associate with the translocon to modify translocating polypeptide chains. J. Biol. Chem. 2014, 289, 8599-8611. [CrossRef] [PubMed]

12. Loibl, M.; Strahl, S. Protein O-mannosylation: What we have learned from baker's yeast. Biochim. Biophys. Acta 2013, 1833, 2438-2446. [CrossRef] [PubMed]

13. Girrbach, V.; Strahl, S. Members of the evolutionarily conserved PMT family of protein O-mannosyltransferases form distinct protein complexes among themselves. J. Biol. Chem. 2003, 278, 12554-12562. [CrossRef] [PubMed]

14. Neubert, P.; Halim, A.; Zauser, M.; Essig, A.; Joshi, H.J.; Zatorska, E.; Larsen, I.S.; Loibl, M.; Castells-Ballester, J.; Aebi, M.; et al. Mapping the O-mannose glycoproteome in saccharomyces cerevisiae. Mol. Cell. Proteom. MCP 2016, 15, 1323-1337. [CrossRef] [PubMed]

15. Travers, K.J.; Patil, C.K.; Wodicka, L.; Lockhart, D.J.; Weissman, J.S.; Walter, P. Functional and genomic analyses reveal an essential coordination between the unfolded protein response and ER-associated degradation. Cell 2000, 101, 249-258. [CrossRef]

16. Arroyo, J.; Hutzler, J.; Bermejo, C.; Ragni, E.; Garcia-Cantalejo, J.; Botias, P.; Piberger, H.; Schott, A.; Sanz, A.B.; Strahl, S. Functional and genomic analyses of blocked protein O-mannosylation in baker's yeast. Mol. Microbiol. 2011, 79, 1529-1546. [CrossRef]

17. Hetz, C. The unfolded protein response: Controlling cell fate decisions under ER stress and beyond. Nat. Rev. Mol. Cell Biol. 2012, 13, 89-102. [CrossRef]

18. Xu, C.; Ng, D.T. Glycosylation-directed quality control of protein folding. Nat. Rev. Mol. Cell Biol. 2015, 16, 742-752. [CrossRef]

19. Xu, C.; Wang, S.; Thibault, G.; Ng, D.T. Futile protein folding cycles in the ER are terminated by the unfolded protein O-mannosylation pathway. Science 2013, 340, 978-981. [CrossRef]

20. Hirayama, H.; Fujita, M.; Yoko-o, T.; Jigami, Y. O-mannosylation is required for degradation of the endoplasmic reticulum-associated degradation substrate Gas $1^{*} \mathrm{p}$ via the ubiquitin/proteasome pathway in Saccharomyces cerevisiae. J. Biochem. 2008, 143, 555-567. [CrossRef]

21. Coughlan, C.M.; Walker, J.L.; Cochran, J.C.; Wittrup, K.D.; Brodsky, J.L. Degradation of mutated bovine pancreatic trypsin inhibitor in the yeast vacuole suggests post-endoplasmic reticulum protein quality control. J. Biol. Chem. 2004, 279, 15289-15297. [CrossRef] [PubMed]

22. Nakatsukasa, K.; Okada, S.; Umebayashi, K.; Fukuda, R.; Nishikawa, S.; Endo, T. Roles of O-mannosylation of aberrant proteins in reduction of the load for endoplasmic reticulum chaperones in yeast. J. Biol. Chem. 2004, 279, 49762-49772. [CrossRef] [PubMed]

23. Harty, C.; Strahl, S.; Romisch, K. O-mannosylation protects mutant alpha-factor precursor from endoplasmic reticulum-associated degradation. Mol. Biol. Cell 2001, 12, 1093-1101. [CrossRef] [PubMed]

24. Vashist, S.; Kim, W.; Belden, W.J.; Spear, E.D.; Barlowe, C.; Ng, D.T. Distinct retrieval and retention mechanisms are required for the quality control of endoplasmic reticulum protein folding. J. Cell Biol. 2001, 155, 355-368. [CrossRef] [PubMed]

25. Murakami-Sekimata, A.; Sato, K.; Sato, K.; Takashima, A.; Nakano, A. O-Mannosylation is required for the solubilization of heterologously expressed human beta-amyloid precursor protein in Saccharomyces cerevisiae. Genes Cells Devoted Mol. Cell. Mech. 2009, 14, 205-215. [CrossRef] [PubMed]

26. Goder, V.; Melero, A. Protein O-mannosyltransferases participate in ER protein quality control. J. Cell Sci. 2011, 124, 144-153. [CrossRef]

27. Fisher, A.C.; DeLisa, M.P. Laboratory evolution of fast-folding green fluorescent protein using secretory pathway quality control. PLOS ONE 2008, 3, e2351. [CrossRef]

28. Winterhalter, P.R.; Lommel, M.; Ruppert, T.; Strahl, S. O-glycosylation of the non-canonical T-cadherin from rabbit skeletal muscle by single mannose residues. Febs Lett. 2013, 587, 3715-3721. [CrossRef]

29. Cronin, S.R.; Rao, R.; Hampton, R.Y. Cod1p/Spf1p is a P-type ATPase involved in ER function and Ca ${ }^{2+}$ homeostasis. J. Cell Biol. 2002, 157, 1017-1028. [CrossRef] 
30. Krumpe, K.; Frumkin, I.; Herzig, Y.; Rimon, N.; Ozbalci, C.; Brugger, B.; Rapaport, D.; Schuldiner, M. Ergosterol content specifies targeting of tail-anchored proteins to mitochondrial outer membranes. Mol. Biol. Cell 2012, 23, 3927-3935. [CrossRef]

31. Stevens, K.L.P.; Black, A.L.; Wells, K.M.; Yeo, K.Y.B.; Steuart, R.F.L.; Stirling, C.J.; Schulz, B.L.; Mousley, C.J. Diminished Ost3-dependent N-glycosylation of the BiP nucleotide exchange factor Sil1 is an adaptive response to reductive ER stress. Proc. Natl. Acad. Sci. USA 2017, 114, 12489-12494. [CrossRef] [PubMed]

32. Preissler, S.; Reuther, J.; Koch, M.; Scior, A.; Bruderek, M.; Frickey, T.; Deuerling, E. Not4-dependent translational repression is important for cellular protein homeostasis in yeast. Embo J. 2015, 34, 1905-1924. [CrossRef] [PubMed]

33. Hashimoto, H.; Sakakibara, A.; Yamasaki, M.; Yoda, K. Saccharomyces cerevisiae VIG9 encodes GDP-mannose pyrophosphorylase, which is essential for protein glycosylation. J. Biol. Chem. 1997, 272, 16308-16314. [CrossRef] [PubMed]

34. Giaever, G.; Chu, A.M.; Ni, L.; Connelly, C.; Riles, L.; Veronneau, S.; Dow, S.; Lucau-Danila, A.; Anderson, K.; Andre, B.; et al. Functional profiling of the Saccharomyces cerevisiae genome. Nature 2002, 418, 387-391. [CrossRef] [PubMed]

35. Breslow, D.K.; Cameron, D.M.; Collins, S.R.; Schuldiner, M.; Stewart-Ornstein, J.; Newman, H.W.; Braun, S.; Madhani, H.D.; Krogan, N.J.; Weissman, J.S. A comprehensive strategy enabling high-resolution functional analysis of the yeast genome. Nat. Methods 2008, 5, 711-718. [CrossRef] [PubMed]

36. Breker, M.; Gymrek, M.; Schuldiner, M. A novel single-cell screening platform reveals proteome plasticity during yeast stress responses. J. Cell Biol. 2013, 200, 839-850. [CrossRef]

37. Jackson, C.L.; Kepes, F. BFR1, a multicopy suppressor of brefeldin A-induced lethality, is implicated in secretion and nuclear segregation in Saccharomyces cerevisiae. Genetics 1994, 137, 423-437.

38. Lang, B.D.; Li, A.; Black-Brewster, H.D.; Fridovich-Keil, J.L. The brefeldin A resistance protein Bfr1p is a component of polyribosome-associated mRNP complexes in yeast. Nucleic Acids Res. 2001, 29, 2567-2574. [CrossRef]

39. Simpson, C.E.; Lui, J.; Kershaw, C.J.; Sims, P.F.; Ashe, M.P. mRNA localization to P-bodies in yeast is bi-phasic with many mRNAs captured in a late Bfr1p-dependent wave. J. Cell Sci. 2014, 127, 1254-1262. [CrossRef]

40. Weidner, J.; Wang, C.; Prescianotto-Baschong, C.; Estrada, A.F.; Spang, A. The polysome-associated proteins Scp160 and Bfr1 prevent P body formation under normal growth conditions. J. Cell Sci. 2014, 127, 1992-2004. [CrossRef]

41. Hogan, D.J.; Riordan, D.P.; Gerber, A.P.; Herschlag, D.; Brown, P.O. Diverse RNA-binding proteins interact with functionally related sets of RNAs, suggesting an extensive regulatory system. PLoS Biol. 2008, 6, e255. [CrossRef] [PubMed]

42. Lapointe, C.P.; Wilinski, D.; Saunders, H.A.; Wickens, M. Protein-RNA networks revealed through covalent RNA marks. Nat. Methods 2015, 12, 1163-1170. [CrossRef] [PubMed]

43. Deshaies, R.J.; Schekman, R. A yeast mutant defective at an early stage in import of secretory protein precursors into the endoplasmic reticulum. J. Cell Biol. 1987, 105, 633-645. [CrossRef] [PubMed]

44. Rose, M.D.; Misra, L.M.; Vogel, J.P. KAR2, a karyogamy gene, is the yeast homolog of the mammalian BiP/GRP78 gene. Cell 1989, 57, 1211-1221. [CrossRef]

45. Karaoglu, D.; Kelleher, D.J.; Gilmore, R. Functional characterization of Ost3p. Loss of the 34-kD subunit of the Saccharomyces cerevisiae oligosaccharyltransferase results in biased underglycosylation of acceptor substrates. J. Cell Biol. 1995, 130, 567-577. [CrossRef]

46. Te Heesen, S.; Janetzky, B.; Lehle, L.; Aebi, M. The yeast WBP1 is essential for oligosaccharyl transferase activity in vivo and in vitro. Embo J. 1992, 11, 2071-2075. [CrossRef]

47. Nuoffer, C.; Jeno, P.; Conzelmann, A.; Riezman, H. Determinants for glycophospholipid anchoring of the Saccharomyces cerevisiae GAS1 protein to the plasma membrane. Mol. Cell. Biol. 1991, 11, 27-37. [CrossRef]

48. Aviram, N.; Schuldiner, M. Targeting and translocation of proteins to the endoplasmic reticulum at a glance. J. Cell Sci. 2017, 130, 4079-4085. [CrossRef]

49. Gilmore, R.; Blobel, G.; Walter, P. Protein translocation across the endoplasmic reticulum. I. Detection in the microsomal membrane of a receptor for the signal recognition particle. J. Cell Biol. 1982, 95, 463-469. [CrossRef]

50. Meyer, D.I.; Krause, E.; Dobberstein, B. Secretory protein translocation across membranes-the role of the “docking protein". Nature 1982, 297, 647-650. [CrossRef] 
51. Singer-Kruger, B.; Jansen, R.P. Here, there, everywhere. mRNA localization in budding yeast. Rna Biol. 2014, 11, 1031-1039. [CrossRef]

52. Kraut-Cohen, J.; Afanasieva, E.; Haim-Vilmovsky, L.; Slobodin, B.; Yosef, I.; Bibi, E.; Gerst, J.E. Translationand SRP-independent mRNA targeting to the endoplasmic reticulum in the yeast Saccharomyces cerevisiae. Mol. Biol. Cell 2013, 24, 3069-3084. [CrossRef]

53. Pyhtila, B.; Zheng, T.; Lager, P.J.; Keene, J.D.; Reedy, M.C.; Nicchitta, C.V. Signal sequence- and translation-independent mRNA localization to the endoplasmic reticulum. RNA 2008, 14, 445-453. [CrossRef] [PubMed]

54. Ingolia, N.T.; Ghaemmaghami, S.; Newman, J.R.; Weissman, J.S. Genome-wide analysis in vivo of translation with nucleotide resolution using ribosome profiling. Science 2009, 324, 218-223. [CrossRef] [PubMed]

55. Brar, G.A.; Weissman, J.S. Ribosome profiling reveals the what, when, where and how of protein synthesis. Nat. Rev. Mol. Cell Biol. 2015, 16, 651-664. [CrossRef] [PubMed]

56. Ast, T.; Cohen, G.; Schuldiner, M. A network of cytosolic factors targets SRP-independent proteins to the endoplasmic reticulum. Cell 2013, 152, 1134-1145. [CrossRef]

57. Zhu, A.; Ibrahim, J.G.; Love, M.I. Heavy-tailed prior distributions for sequence count data: Removing the noise and preserving large differences. Bioinformatics 2019, 35, 2084-2092. [CrossRef]

58. Castells-Ballester, J.; Zatorska, E.; Meurer, M.; Neubert, P.; Metschies, A.; Knop, M.; Strahl, S. Monitoring protein dynamics in protein o-mannosyltransferase mutants in vivo by tandem fluorescent protein timers. Molecules 2018, 23, 2622. [CrossRef]

59. Xu, C.; Ng, D.T. O-mannosylation: The other glycan player of ER quality control. Semin. Cell Dev. Biol. 2015, 41, 129-134. [CrossRef]

60. Ambroziak, J.; Henry, S.A. INO2 and INO4 gene products, positive regulators of phospholipid biosynthesis in Saccharomyces cerevisiae, form a complex that binds to the INO1 promoter. J. Biol. Chem. 1994, 269, 15344-15349.

61. Shyu, P., Jr.; Ng, B.S.H.; Ho, N.; Chaw, R.; Seah, Y.L.; Marvalim, C.; Thibault, G. Membrane phospholipid alteration causes chronic ER stress through early degradation of homeostatic ER-resident proteins. Sci. Rep. 2019, 9, 8637. [CrossRef] [PubMed]

62. Sorensen, D.M.; Holen, H.W.; Pedersen, J.T.; Martens, H.J.; Silvestro, D.; Stanchev, L.D.; Costa, S.R.; Gunther Pomorski, T.; Lopez-Marques, R.L.; Palmgren, M. The P5A ATPase Spf1p is stimulated by phosphatidylinositol 4-phosphate and influences cellular sterol homeostasis. Mol. Biol. Cell 2019, 30, 1069-1084. [CrossRef] [PubMed]

63. Torres-Quiroz, F.; Garcia-Marques, S.; Coria, R.; Randez-Gil, F.; Prieto, J.A. The activity of yeast Hog1 MAPK is required during endoplasmic reticulum stress induced by tunicamycin exposure. J. Biol. Chem. 2010, 285, 20088-20096. [CrossRef] [PubMed]

64. Burg, M.B.; Ferraris, J.D. Intracellular organic osmolytes: Function and regulation. J. Biol. Chem. 2008, 283, 7309-7313. [CrossRef]

65. Guerra-Moreno, A.; Ang, J.; Welsch, H.; Jochem, M.; Hanna, J. Regulation of the unfolded protein response in yeast by oxidative stress. Febs Lett. 2019, 593, 1080-1088. [CrossRef]

66. Carla Fama, M.; Raden, D.; Zacchi, N.; Lemos, D.R.; Robinson, A.S.; Silberstein, S. The Saccharomyces cerevisiae YFR041C/ERJ5 gene encoding a type I membrane protein with a J domain is required to preserve the folding capacity of the endoplasmic reticulum. Biochim. Biophys. Acta 2007, 1773, 232-242. [CrossRef]

67. Copic, A.; Dorrington, M.; Pagant, S.; Barry, J.; Lee, M.C.; Singh, I.; Hartman, J.L.t.; Miller, E.A. Genomewide analysis reveals novel pathways affecting endoplasmic reticulum homeostasis, protein modification and quality control. Genetics 2009, 182, 757-769. [CrossRef]

68. Bays, N.W.; Gardner, R.G.; Seelig, L.P.; Joazeiro, C.A.; Hampton, R.Y. Hrd1p/Der3p is a membrane-anchored ubiquitin ligase required for ER-associated degradation. Nat. Cell Biol. 2001, 3, 24-29. [CrossRef]

69. Kostova, Z.; Wolf, D.H. For whom the bell tolls: Protein quality control of the endoplasmic reticulum and the ubiquitin-proteasome connection. Embo J. 2003, 22, 2309-2317. [CrossRef]

70. Schwarz, M.; Knauer, R.; Lehle, L. Yeast oligosaccharyltransferase consists of two functionally distinct sub-complexes, specified by either the Ost3p or Ost6p subunit. Febs Lett. 2005, 579, 6564-6568. [CrossRef]

71. Zatorska, E.; Gal, L.; Schmitt, J.; Bausewein, D.; Schuldiner, M.; Strahl, S. Cellular consequences of diminished protein o-mannosyltransferase activity in baker's yeast. Int. J. Mol. Sci. 2017, 18, 1226. [CrossRef] [PubMed] 
72. Janik, A.; Sosnowska, M.; Kruszewska, J.; Krotkiewski, H.; Lehle, L.; Palamarczyk, G. Overexpression of GDP-mannose pyrophosphorylase in Saccharomyces cerevisiae corrects defects in dolichol-linked saccharide formation and protein glycosylation. Biochim. Biophys. Acta 2003, 1621, 22-30. [CrossRef]

73. Zakrzewska, A.; Palamarczyk, G.; Krotkiewski, H.; Zdebska, E.; Saloheimo, M.; Penttila, M.; Kruszewska, J.S. Overexpression of the gene encoding GTP:mannose-1-phosphate guanyltransferase, mpg1, increases cellular GDP-mannose levels and protein mannosylation in Trichoderma reesei. Appl. Environ. Microbiol. 2003, 69, 4383-4389. [CrossRef] [PubMed]

74. Luo, Y.; Na, Z.; Slavoff, S.A. P-Bodies: Composition, Properties, and Functions. Biochemistry 2018, 57, 2424-2431. [CrossRef]

75. Albihlal, W.S.; Gerber, A.P. Unconventional RNA-binding proteins: An uncharted zone in RNA biology. Febs Lett. 2018, 592, 2917-2931. [CrossRef]

76. Mitchell, S.F.; Jain, S.; She, M.; Parker, R. Global analysis of yeast mRNPs. Nat. Struct. Mol. Biol. 2013, 20, 127-133. [CrossRef]

77. Zweytick, D.; Hrastnik, C.; Kohlwein, S.D.; Daum, G. Biochemical characterization and subcellular localization of the sterol C-24(28) reductase, erg4p, from the yeast saccharomyces cerevisiae. Febs Lett. 2000, 470, 83-87. [CrossRef]

78. Manchalu, S.; Mittal, N.; Spang, A.; Jansen, R.P. Local translation of yeast ERG4 mRNA at the endoplasmic reticulum requires the brefeldin A resistance protein Bfr1. RNA 2019, 25, 1661-1672. [CrossRef]

79. Mueller, S.; Wahlander, A.; Selevsek, N.; Otto, C.; Ngwa, E.M.; Poljak, K.; Frey, A.D.; Aebi, M.; Gauss, R. Protein degradation corrects for imbalanced subunit stoichiometry in OST complex assembly. Mol. Biol. Cell 2015, 26, 2596-2608. [CrossRef]

80. Cohen, N.; Breker, M.; Bakunts, A.; Pesek, K.; Chas, A.; Argemi, J.; Orsi, A.; Gal, L.; Chuartzman, S.; Wigelman, Y.; et al. Iron affects Ire1 clustering propensity and the amplitude of endoplasmic reticulum stress signaling. J. Cell Sci. 2017, 130, 3222-3233. [CrossRef]

81. Brachmann, C.B.; Davies, A.; Cost, G.J.; Caputo, E.; Li, J.; Hieter, P.; Boeke, J.D. Designer deletion strains derived from Saccharomyces cerevisiae S288C: A useful set of strains and plasmids for PCR-mediated gene disruption and other applications. Yeast 1998, 14, 115-132. [CrossRef]

82. Robinson, J.S.; Klionsky, D.J.; Banta, L.M.; Emr, S.D. Protein sorting in Saccharomyces cerevisiae: Isolation of mutants defective in the delivery and processing of multiple vacuolar hydrolases. Mol. Cell. Biol. 1988, 8 , 4936-4948. [CrossRef] [PubMed]

83. Papic, D.; Elbaz-Alon, Y.; Koerdt, S.N.; Leopold, K.; Worm, D.; Jung, M.; Schuldiner, M.; Rapaport, D. The role of Djp1 in import of the mitochondrial protein Mim1 demonstrates specificity between a cochaperone and its substrate protein. Mol. Cell. Biol. 2013, 33, 4083-4094. [CrossRef] [PubMed]

84. Taxis, C.; Knop, M. System of centromeric, episomal, and integrative vectors based on drug resistance markers for Saccharomyces cerevisiae. Biotechniques 2006, 40, 73-78. [CrossRef] [PubMed]

85. Christianson, T.W.; Sikorski, R.S.; Dante, M.; Shero, J.H.; Hieter, P. Multifunctional yeast high-copy-number shuttle vectors. Gene 1992, 110, 119-122. [CrossRef]

86. Guldener, U.; Heck, S.; Fielder, T.; Beinhauer, J.; Hegemann, J.H. A new efficient gene disruption cassette for repeated use in budding yeast. Nucleic Acids Res. 1996, 24, 2519-2524. [CrossRef]

87. Hutzler, F.; Gerstl, R.; Lommel, M.; Strahl, S. Protein N-glycosylation determines functionality of the Saccharomyces cerevisiae cell wall integrity sensor Mid2p. Mol. Microbiol. 2008, 68, 1438-1449. [CrossRef]

88. Tong, A.H.; Boone, C. Synthetic genetic array analysis in Saccharomyces cerevisiae. Methods Mol. Biol. 2006, 313, 171-192.

89. Cohen, Y.; Schuldiner, M. Advanced methods for high-throughput microscopy screening of genetically modified yeast libraries. Methods Mol. Biol. 2011, 781, 127-159.

90. Gentzsch, M.; Immervoll, T.; Tanner, W. Protein O-glycosylation in Saccharomyces cerevisiae: The protein O-mannosyltransferases Pmt1p and Pmt2p function as heterodimer. Febs Lett. 1995, 377, 128-130. [CrossRef]

91. Stirling, C.J.; Rothblatt, J.; Hosobuchi, M.; Deshaies, R.; Schekman, R. Protein translocation mutants defective in the insertion of integral membrane proteins into the endoplasmic reticulum. Mol. Biol. Cell 1992, 3, 129-142. [CrossRef] [PubMed]

92. Popolo, L.; Grandori, R.; Vai, M.; Lacana, E.; Alberghina, L. Immunochemical characterization of gp115, a yeast glycoprotein modulated by the cell cycle. Eur. J. Cell Biol. 1988, 47, 173-180. [PubMed] 
93. Te Heesen, S.; Knauer, R.; Lehle, L.; Aebi, M. Yeast Wbp1p and Swp1p form a protein complex essential for oligosaccharyl transferase activity. Embo J. 1993, 12, 279-284. [CrossRef] [PubMed]

94. Aronov, S.; Dover-Biterman, S.; Suss-Toby, E.; Shmoish, M.; Duek, L.; Choder, M. Pheromone-encoding mRNA is transported to the yeast mating projection by specific RNP granules. J. Cell Biol. 2015, 209, 829-842. [CrossRef] [PubMed]

95. Doring, K.; Ahmed, N.; Riemer, T.; Suresh, H.G.; Vainshtein, Y.; Habich, M.; Riemer, J.; Mayer, M.P.; O’Brien, E.P.; Kramer, G.; et al. Profiling Ssb-nascent chain interactions reveals principles of Hsp70-assisted folding. Cell 2017, 170, 298-311.e220. [CrossRef] [PubMed]

96. Galmozzi, C.V.; Merker, D.; Friedrich, U.A.; Doring, K.; Kramer, G. Selective ribosome profiling to study interactions of translating ribosomes in yeast. Nat. Protoc. 2019, 14, 2279-2317. [CrossRef]

97. Love, M.I.; Huber, W.; Anders, S. Moderated estimation of fold change and dispersion for RNA-seq data with DESeq2. Genome Biol. 2014, 15, 550. [CrossRef]

98. Benjamini, Y.; Hochberg, Y. Controlling the false discovery rate: A practical and powerful approach to multiple testing. J. R. Stat. Soc. Ser. B 1995, 57, 289-300. [CrossRef]

99. Ignatiadis, N.; Klaus, B.; Zaugg, J.B.; Huber, W. Data-driven hypothesis weighting increases detection power in genome-scale multiple testing. Nat. Methods 2016, 13, 577-580. [CrossRef]

(C) 2019 by the authors. Licensee MDPI, Basel, Switzerland. This article is an open access article distributed under the terms and conditions of the Creative Commons Attribution (CC BY) license (http://creativecommons.org/licenses/by/4.0/). 